\title{
Cellular Physiology of the Turtle Visual Cortex: Synaptic Properties and Intrinsic Circuitry
}

\author{
Arnold R. Kriegstein and Barry W. Connors \\ Department of Neurology, Stanford University School of Medicine, Stanford, California 94305
}

We have examined the synaptic physiology of the isolated dorsal cortex of the turtle, Pseudemys scripta elegans. Electrical stimulation of afferent pathways elicited distinct, stereotyped responses in pyramidal and stellate neurons. Single shocks evoked a long-lasting barrage of excitatory postsynaptic potentials (EPSPs) in stellate cells, and led to a burst of several action potentials. Under the same circumstances, pyramidal cells displayed a small amount of short-latency excitation, but this was accompanied by a profound and prolonged set of inhibitory postsynaptic potentials (IPSPs). Synaptic excitation of the distal dendrites of pyramidal cells could evoke dendritic action potentials that were visible at the soma as small all-or-none spikes rising from the hyperpolarized level of the IPSP.

There appeared to be two mechanistically different types of IPSPs in pyramidal cells. The first occurred at short latency, could produce a very large conductance increase, reversed polarity at $-71 \mathrm{mV}$, and was chloride-dependent. The second was generally smaller and more protracted, had a relatively negative reversal potential of -85 to $-95 \mathrm{mV}$, and was insensitive to chloride injection. Focal application of small doses of the putative inhibitory neurotransmitter $\gamma$-aminobutyric acid (GABA) onto the somata of pyramidal cells caused a conductance increase and hyperpolarization. This response had features in common with the short-latency IPSP, including an identical reversal potential. Application of large doses of GABA to the somata of pyramidal cells or smaller doses to their dendrites elicited multiphasic or purely depolarizing responses that were at least partly due to time- or space-dependent shifts of the equilibrium potential of the response. Bicuculline methiodide, a potent GABA antagonist, depressed both the responses to GABA and the short-latency IPSP, but not the long-latency IPSP; synchronized epileptiform burst discharges also resulted.

These findings, together with responses to locally applied electric shocks and the excitatory amino acid glutamate, suggested that inhibition of pyramidal cells was generated intrinsically by stellate cells, and that the cortical circuit provides pathways for both feedforward and feedback GABAergic inhibition. The data also suggest that pyramidal cells are mutually excitatory. These features are similar to the basic intrinsic circuitry in the telencephalic cortices of mammals.

Received Apr. 2, 1985; revised July 8, 1985; accepted July 11, 1985.
We thank Robert E. Foster for introducing us to the turtle cortex, Bruce R.
Ransom for participating in some of the early experiments, and K. L. Chow, P.
H. Desan, and D. A. McCormick for critical comments on the manuscript. We
also acknowledge the excellent technical assistance of Jay Kadis and manuscript
preparation by Marie Holt and Cheryl Joo. These studies were supported by the
Klingenstein Fund and NIH Grants NS 12151 , NS 00887 , and NS 21223 .
Correspondence should be addressed to Arnold R. Kriegstein, M.D., Ph.D.,
Department of Neurology, Stanford University Medical Center, Stanford, CA
94305 .
Copyright (C) 1986 Society for Neuroscience $0270-6474 / 86 / 010178-14 \$ 02.00 / 0$
The dorsal cortex of reptiles is phylogenetically related to the mammalian neocortex and has many of the same afferent and efferent connections (Desan, 1984; Hall and Ebner, 1970; Hall et al., 1977; Hohmann et al., 1983; Ouimet and Ebner, 1981; Parent and Poitras, 1974; Smith et al., 1980). The relatively simple structure of turtle cortex has enabled us to undertake a comparative study of its principal neuronal elements (Connors and Kriegstein, 1986). The dorsal (or general) cortex of turtles consists of two basic neuron types, pyramidal and stellate, each with a characteristic structure and physiology. The synaptic relationships of these neurons are poorly understood. However, quantitative studies of the cortical fine structure have allowed some interesting predictions concerning the function of cortical connectivity. Thalamocortical afferents terminate in the upper $100 \mu \mathrm{m}$ of cortex on dendrites of both pyramidal and stellate cells (Hall and Ebner, 1970), with each stellate cell receiving at least six times more thalamic fiber synapses than each pyramidal cell (Smith et al., 1980). Stellate cell axons are presumed to give rise to the synapses with flattened vesicles and symmetrical profiles prevalent within the molecular layer and on pyramidal cell somata (Ebner and Colonnier, 1975, 1978). Since synapses of this type are often correlated with inhibitory function (Atwood et al., 1972; Uchizono, 1965), Smith et al. (1980) inferred that thalamic volleys would elicit direct excitation of pyramidal cells, followed by feed-forward inhibition mediated by stellate cells. As a corollary, thalamic input should powerfully excite stellate neurons.

The few extant physiological studies of turtle cortex are basically consistent with the anatomical data. Stimulation of the optic nerve evokes a negative surface potential on the cortex that is rapidly depressed during repetitive activation (Belekhova, 1965; Karamian et al., 1966; Mazurskaya et al., 1966). In addition, the electrophysiology suggests that some thalamocortical synapses are potentiated following single stimuli, and that a system of recurrent inhibition exists (Orrego and Lisenby, 1962). The purposes of the present study are to clarify further the intrinsic circuitry of the cortex, characterize the synaptic physiology, and begin to identify some of the local neurotransmitters. The results demonstrate many similarities between the basic synaptic mechanisms of turtle dorsal cortex and those of several mammalian cortical structures (Connors et al., 1983; Kriegstein and Connors, 1984).

\section{Materials and Methods}

The general methods were identical to those of the preceding paper (Connors and Kriegstein, 1986), with the following additions. We sometimes utilized a coronal slice preparation as an alternative to the intact cortex described previously. In this case the entire brain was removed from the skull, hemisected and placed in cold turtle saline solution. Scalpel cuts were made in the coronal plane to remove the anterior and posterior poles. The remaining block of tissue, which contained the dorsal cortex, medial and lateral cortices, and subcortical structures, was attached to the stage of a Vibratome (Lancer, Series 1000) with cyanoacrylate glue and immersed in cold physiological solution. In some 


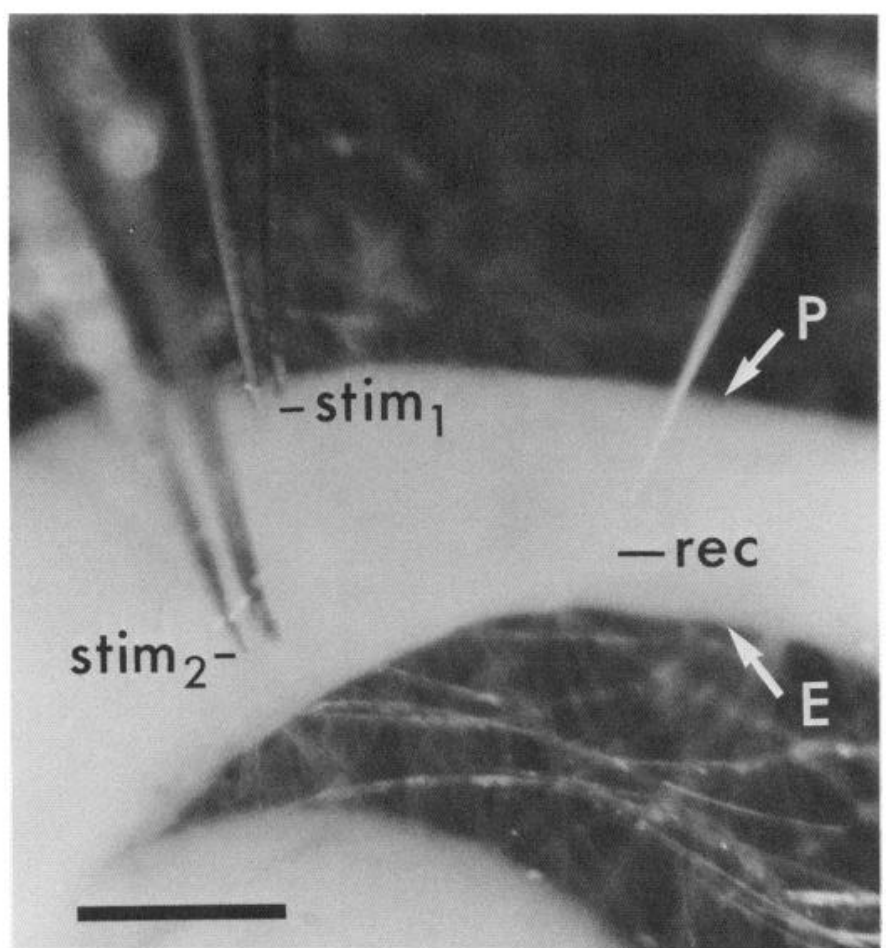

Figure 1. A vibratomed section of living turtle cortex, as viewed in place in the recording chamber. The cortex has been sliced coronally at a thickness of about $500 \mu \mathrm{m}$. It rests on a single sheet of filter paper and is superfused with normal turtle saline. The cortical mantle is about 500-900 $\mu \mathrm{m}$ wide, bordered by the pial $(P)$ surface and by the ependymal $(E)$ layer. The curved structure in the lower part is the dorsal ventricular ridge. Bipolar tungsten electrodes provide stimulation of axons in the molecular layer $\left(\right.$ stim $\left._{1}\right)$ or in the subcellular zone $\left(\right.$ stim $\left._{2}\right)$. A glass microelectrode records from the pyramidal cell layer $(\mathrm{rec})$. Medial is to the right. Scale bar $=500 \mu \mathrm{m}$.

experiments the tissue was first embedded in $3 \%$ agar in physiological saline to provide stability while cutting. Coronal slices $500 \mu \mathrm{m}$ thick were made and placed in the recording chamber. Figure 1 illustrates such a slice. The great advantage of this method was that stimulating and recording electrodes could be placed in visually identified areas of the cortex.

In some experiments, 5-10 $\mathrm{mm} \gamma$-aminobutyric acid (GABA) or L-glutamate (Sigma) dissolved in normal turtle solution was focally released from a micropipette (3-5 $\mu$ m diameter tip). Pulses of compressed $\mathrm{N}_{2}$ $\left(2-3.5 \mathrm{~kg} / \mathrm{cm}^{2}\right)$ were applied for 5-1000 msec using a rapidly switching solenoid valve (General Valve) controlled by a digital stimulator. In some experiments, bicuculline methiodide (Sigma) was dissolved in the bathing solution. Intracellular microelectrodes were filled with $3 \mathrm{M} \mathrm{K}$ acetate, unless otherwise specified.

\section{Results}

\section{Synaptic potentials of pyramidal and stellate cells}

In the previous paper (Connors and Kriegstein, 1986), we showed that the two basic morphological types of neuron in the turtle cortex could be easily differentiated by their action-potential properties alone. The responses of pyramidal and stellate neurons to activation of synaptic pathways also proved to be strikingly different. Single shocks (200 $\mu$ sec duration) were applied to the superficial molecular layer. This would be expected to stimulate a variety of axon systems, including the thalamocortical afferent pathway (Hall and Ebner, 1970). Two representative pyramidal cell responses are shown in Figure 2. At low intensities, stimuli were followed by hyperpolarizations, usually without any preceding depolarization. As intensity was increased, the amplitude of this inhibitory postsynaptic poten-
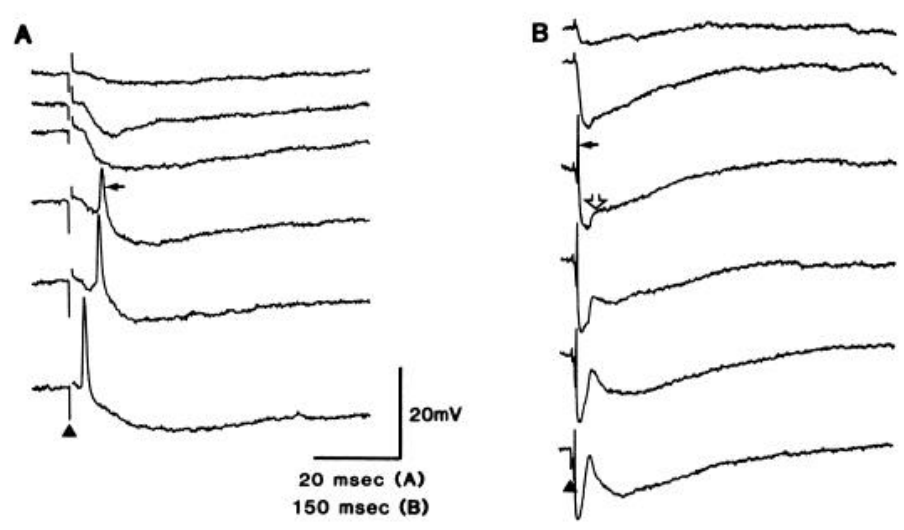

Figure 2. The responses of two pyramidal cells to increasing intensities of orthodromic stimulation. $A$, Intracellular responses are recorded to single shocks (triangle) applied to the superficial molecular layer. As stimulus intensity increases (from top to bottom), a hyperpolarizing IPSP develops and grows in amplitude. In addition, a small spike (arrow) arises out of the hyperpolarizing phase of the IPSP at a discrete threshold. Its latency decreases with increasing stimulus strength, and as it moves farther from the peak conductance increase associated with the IPSP, its amplitude increases. Resting potential $=-60 \mathrm{mV}$. B, The response of another pyramidal cell to stimuli of increasing intensity from the top to the bottom trace. A small spike also appears early in the synaptic response (arrow) and, in addition, a depolarizing wave arises from the IPSP (open arrow) and grows in amplitude with increasing stimulus strength. Resting potential $=-58 \mathrm{mV}$.

tial (IPSP) grew until it peaked at a maximal level of $10-15 \mathrm{mV}$. In the majority of cells, moderate stimulus currents also evoked one small $(10-20 \mathrm{mV})$ action potenial. These orthodromic spikes (Fig. 2, closed arrows) had several interesting characteristics: they usually occurred at a longer latency than the IPSP onset; their latency was quite variable; they often arose abruptly from the baseline without any obvious prepotentials; their threshold membrane potential, as measured from the somatic recording site, was usually below the resting potential; and their amplitude could vary with the intensity of stimulation, as in the example of Figure $2 A$, where the spike size increased with stronger stimuli, presumably because it was less shunted by the IPSP conductance as its latency decreased. As is elaborated below, we hypothesize that these action potentials originate from dendritic sites. High-intensity stimuli evoked very complex synaptic waveforms (Fig. $2 B$ ) consisting of a short-latency, large-amplitude hyperpolarization, a variably sized decrease in membrane potential, between about 10 and $80 \mathrm{msec}$ (Fig. $2 B$, open arrow), and, finally, a long-duration hyperpolarization that lasted several hundred msec.

In contrast, molecular-layer stimuli evoked strong excitation in stellate cells (Fig. 3). These responses consisted of summated excitatory postsynaptic potentials (EPSPs) that could continue as long as $400 \mathrm{msec}$, and at moderate stimulus intensities the depolarizing wave evoked a train of action potentials. There was no obvious synaptic inhibition associated with the orthodromic response of most stellate cells. For example, depolarizing the cell illustrated in Figure $3 A$ with injected current did not reveal any significant hyperpolarizing components that may have been masked by concurrent excitation. However, two stellate cells out of a total of 12 tested did show a biphasic response consisting of early excitation followed by a longer-latency IPSP that was apparent when the membrane was depolarized (Fig. $3 B)$.

\section{Pyramidal cell PSPs: Excitation}

Ultrastructural studies of the molecular layer of turtle dorsal cortex have demonstrated that thalamocortical afferents form 

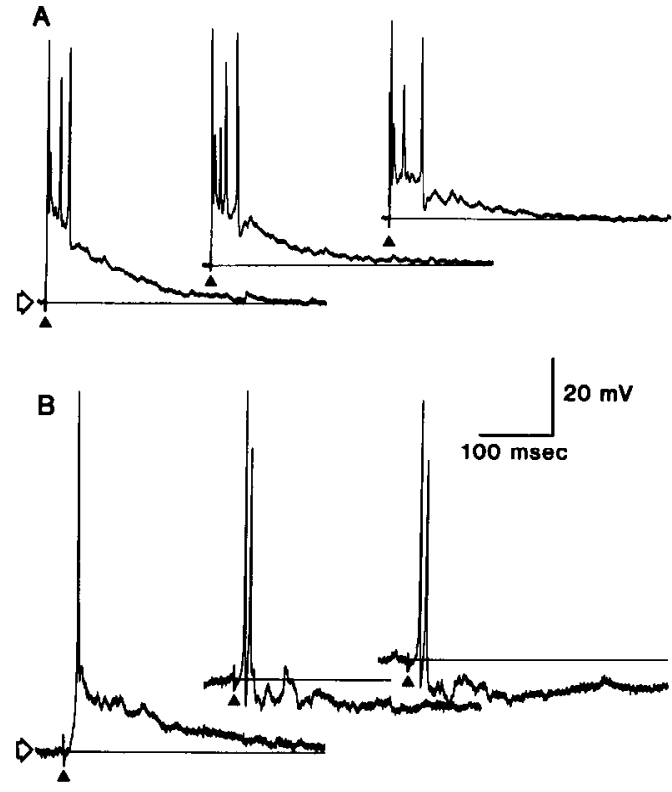

Figure 3. Orthodromic stimulation of stellate cells produces excitatory synaptic responses. $A$, Intracellular response of a stellate cell to electrical stimulation of the molecular layer (triangle), shown at resting potential $(-60 \mathrm{mV}$, open arrow), and with the cell depolarized to two levels by current injection (right). The response consists of a large, long-lasting EPSP that triggers a burst of spikes, with no indication of inhibition. $B$, Intracellular voltage response of another stellate cell to similar stimulation (triangle). At the resting membrane potential $(-63 \mathrm{mV}$, open arrow), the shock produces depolarization and triggers a spike. When this cell is depolarized with current, as shown at two different levels to the right, the response is seen to contain a mixture of excitatory components as well as hyperpolarizing inhibitory components.

significant numbers of asymmetric terminations on the distal apical dendrites of pyramidal cells (Smith et al., 1980). Thus, afferent activity should excite the principal cells. As the preceding intracellular data show, the pyramidal cell response to stimulation in the molecular layer appears to be predominantly inhibitory. However, the short-latency spikes that were concurrently evoked imply some excitation, which could correspond to synaptic activation of dendrites that are electrotonically remote from the recording site.

Quantitative studies also show that pyramidal cell dendrites reccive cxcitatory terminals from unknown sources throughout their length in the molecular layer and, to a lesser extent, within the subcellular zone (Ebner and Colonnier, 1978). We therefore combined intracellular recordings with field-potential analysis to define more precisely the spatial extent of synaptic excitation. As illustrated in Figure $4 A$ (bottom traces), electrical stimulation of local pathways (in this case from the subcellular layer) occasionally evoked a short-latency EPSP in a recorded pyramidal cell. When the membrane was slightly depolarized the EPSP generated a small-amplitude action potential. Such obvious EPSPs were not observed in most cells. Extracellular recordings under the same stimulation conditions, however, always revealed a negative, usually monophasic, field potential whose latency and time course were similar to the intracellularly recorded EPSPs (Fig. $4 A$, top trace). This component of the field potential is likely to be a measure of synaptic excitation in pyramidal cells. The laminar profiles of extracellular voltage change were examined for a variety of stimulation sites, and the recording arrangement is shown schematically in Figure $4 B$. Stimuli were delivered by monopolar cathodal electrodes. Examples of superimposed records are shown for stimuli to the subcellular layer (Fig. 4C); the form of responses to molecular layer stimuli was very similar. Stimulus sites were $500 \mu \mathrm{m}$ lateral

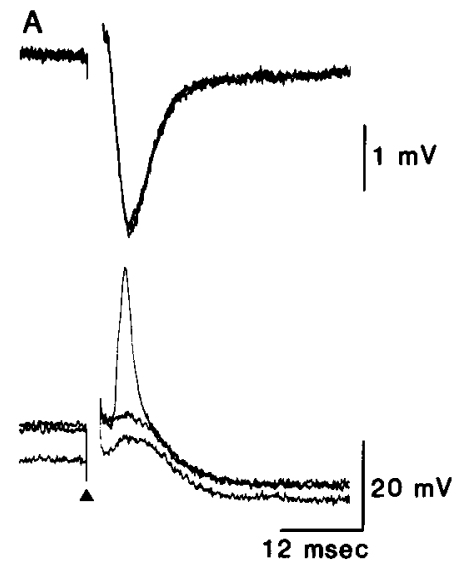

B
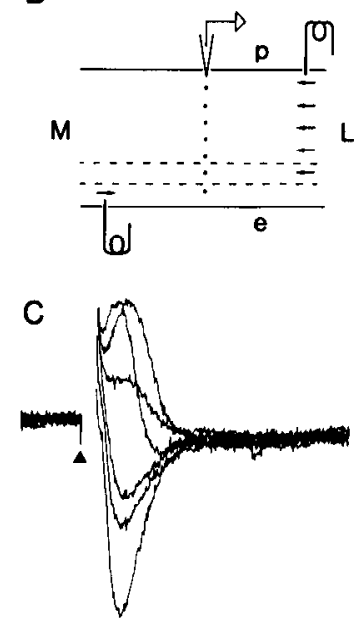

D $\quad 2 m v+$
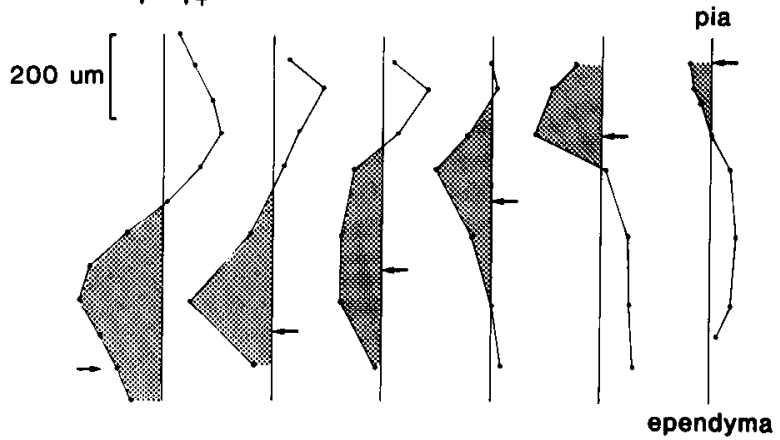

Figure 4. Spatial analysis of extracellular field potentials. $A$, A single stimulus (triangle) was applied to the subcellular zone and the extracellular field (top) and pyramidal cell intracellular (bottom) voltages were monitored near the same site in the cellular layer. Three superimposed traces; negative is down in all recordings. The field potential shows a monophasic negativity that is coincident with a small EPSP in the pyramidal cell. At resting potential, a small spike was sometimes triggered by the EPSP, but slightly hyperpolarizing the membrane blocked the spike. $B$, Schematic diagram of experiment illustrated in $C$ and $D$. Extracellular potentials were recorded at different laminar sites (dots) and monopolar cathodal stimuli were applied at lateral $(L)$ sites in the molecular layer or a medial $(M)$ site in the subcellular layer. Arrows indicate stimulus sites. The lateral distance between recording and stimulating sites was $500 \mu \mathrm{m}$; and the total cortical thickness from pia $(p)$ to ependyma (e) was $875 \mu \mathrm{m}$. The approximate position of the cellular layer is represented by the dashed lines. For each set of data plotted in $D$, the stimulus site was held constant while the recording site was varied sequentially. $C$, Sample responses from subcellular stimuli. These points formed the source for data in $D$, left graph. The form of responses to molecular layer stimuli was similar. $D$, Graphs of laminar extracellular voltage profiles following stimuli to various cortical sites. Voltages were measured at the latency of the peak negative potential for each stimulus site. Stimulus sites are indicated by arrows, and the area under negative potentials is shaded for clarity. Data plotted on the left were evoked by subcellular zone stimuli applied $500 \mu \mathrm{m}$ medial to the line of recording sites. Data for the next five graphs were evoked by stimuli applied 500 $\mu \mathrm{m}$ lateral to recording sites, at progressively more superficial points.

to the axis of the extracellular recording sites, and subcellular layer shocks were delivered medially in order to antidromically activate pyramidal cell efferents, while molecular layer shocks were applied to the lateral side to stimulate afferent pathways more selectively. Figure $4 D$ plots the laminar voltage profiles as measured at the latencies of the largest peak negativities. Each molecular layer stimulus elicited a zone of negativity (shaded areas) that reached a maximal amplitude at roughly the same subpial depth as the stimulation site. Areas far from the stimulus site generated positivities. Although stimuli at the most super- 


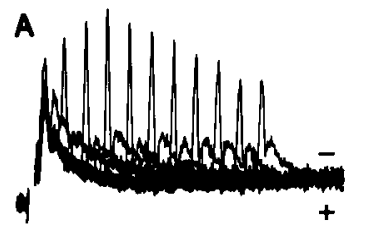

B
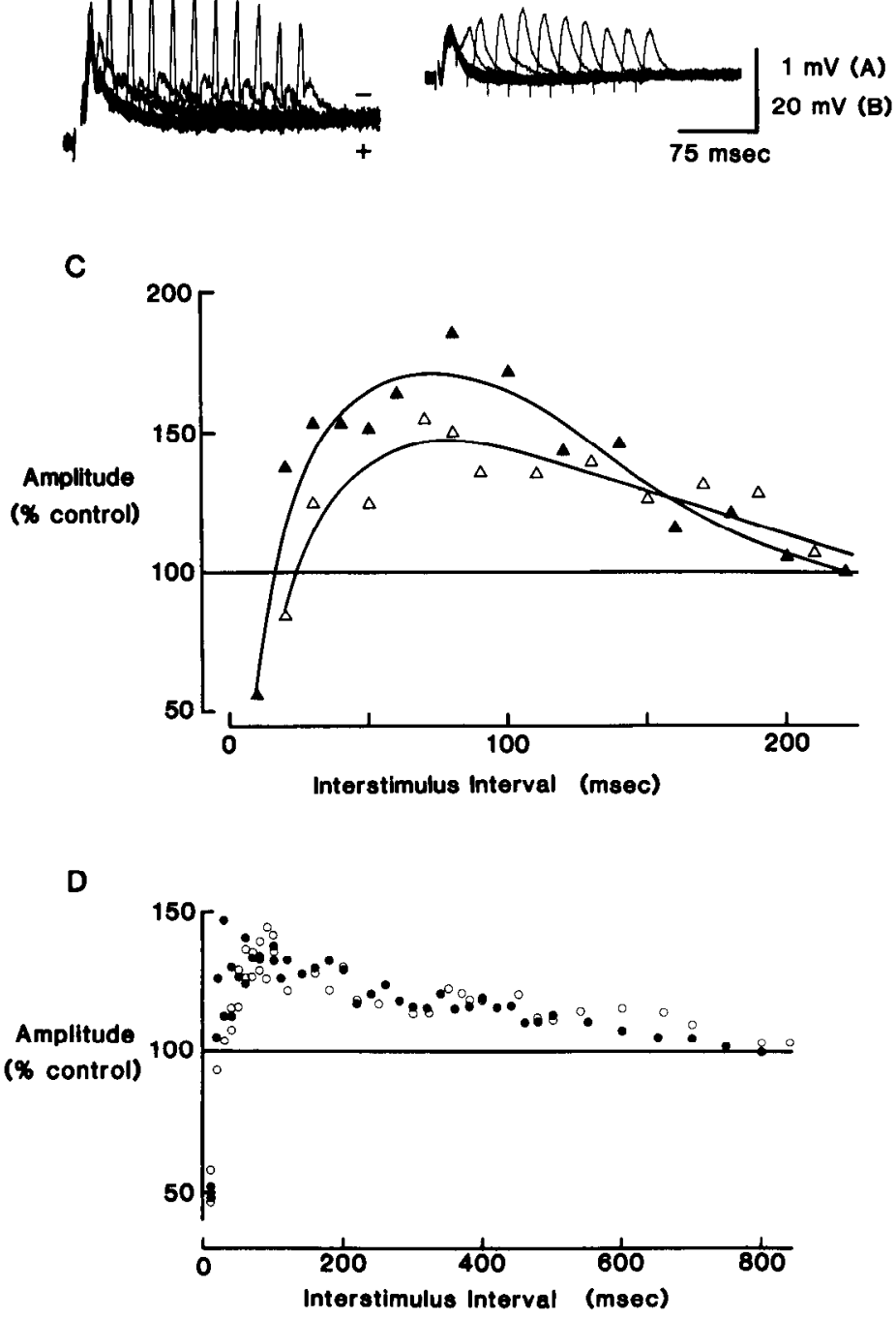

ficial site evoked the smallest negative potentials (Fig. $4 D$, rightmost graph), responses to stimuli in the middle and deep parts of the molecular layer were approximately equal to one another. Subcellular shocks also generated large responses, but the peak negativities were shifted superficially into the deeper aspect of the molecular layer (Fig. $4 D$, leftmost graph). Similar response profiles were obtained with slices from two different animals. Consideration of the cortical anatomy suggests that these fast extracellular negativities are generated by excitatory synaptic current sinks in pyramidal cells, and that the positivities result from distributed dendritic current sources (reviewed by Mitzdorf, 1985). Thus, consistent with anatomical studies of turtle cortex (Desan, 1984; Hall and Ebncr, 1970; Smith ct al., 1980), there seem to be sets of tangentially directed excitatory fibers throughout the molecular layer, similar to the structure of stratum radiatum of the CA1 area of mammalian hippocampus (Andersen et al., 1980). The data are also consistent with a powerful system of recurrent excitation activated by subcellular layer stimuli.

When paired shocks were applied to the molecular layer, the response to the second stimulus was usually smaller than that to the first (not shown), presumably because of the profound inhibition impinging upon pyramidal cells. Such inhibition was maximal at short interstimulus intervals, but could last for several hundred msec. In two of nine coronal slices tested, however,
Figure 5. Paired-pulse potentiation of synaptic transmission in the dorsal cortex. $A$, Extracellular recordings of paired shocks applied to the molecular layer at varying interstimulus intervals. Responses are superimposed, and negativity is upward. Recordings were made in the deep molecular layer. $B$, Intracellular recordings of EPSPs in a pyramidal cell from the same slice; stimulus conditions as in $A$. Membrane potential has been hyperpolarized to near the reversal potential for the short-latency IPSP. Negativity is downward. $C$, Plot of second response amplitude from $A$ (closed triangles) and $B$ (open triangles), expressed as percentages of the unconditioned response, as a function of interstimulus interval. Continuous lines are arbitrary. $D$, Comparison of potentiation evoked by stimuli to the molecular layer (filled circles) and subcellular layer (open circles). Field potentials were recorded in the deep molecular layer in a slice different from the one used for $A-C$. Test responses were normalized to the control amplitudes, and plotted as a function of interstimulus interval. there was a period of prolonged facilitation following an early phase of inhibition. Figure $5 A$ shows paired extracellular responses in one of these preparations. Figure $5 B$ illustrates intracellular recordings from a pyramidal cell in the same slice. In this case the early EPSP was unusually prominent, and the membrane was hyperpolarized to near the reversal potential of the short-latency IPSP. Both records demonstrate marked pairedpulse facilitation. Comparison of the normalized amplitude of the extracellular (Fig. 5C, closed symbols) and intracellular (open symbols) data shows that the peak magnitude of facilitation was greater in the field potential, but that the temporal patterns were similar. In another preparation, facilitation from subcellular layer and molccular layer shocks wcre comparcd. When amplitudes were normalized to control responses, the resulting graphs were virtually superimposable (Fig. $5 D$ ). This behavior is similar to the synaptic facilitation observed in a variety of peripheral and central excitatory synapses (Martin, 1977).

\section{Pyramidal cell PSPs: Inhibition}

Stimuli to the molecular and subcellular layers yielded very similar IPSPs in pyramidal neurons. When compared in a single cell, the reversal potentials of the short-latency IPSPs evoked from both sites were nearly indistinguishable (Fig. 6), although the time course and waveforms of the two synaptic responses usually differed slightly. 
A

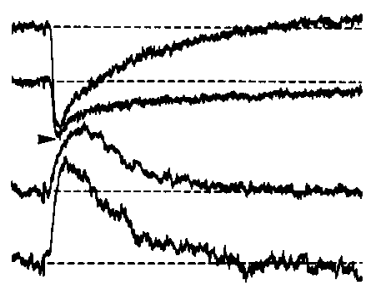

$\triangle$
B

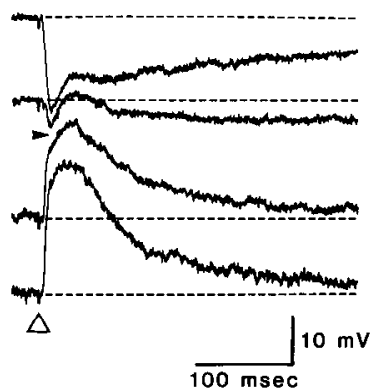

Figure 6. Synaptic responses of pyramidal cells to stimulation in the subcellular and molecular layers are similar. $A$, Voltage response of a pyramidal cell to single shocks to the subcellular zone (open triangle). The shock was applied with the cell polarized to four different levels, from $-47 \mathrm{mV}$ (top) to $-95 \mathrm{mV}$ (bottom), and the short-latency IPSP was inverted at a potential of $-71 \mathrm{mV}$ (arrowhead). $B$, The rcsponsc of the same pyramidal cell shown in $A$ to stimulation applied to the superficial molecular layer (open triangle). The cell is also shown at four different membrane potentials, from $-42 \mathrm{mV}$ (top) to $-100 \mathrm{mV}$ (bottom), and the reversal potential of the early synaptic response (arrowhead) remains similar to the reversal potential recorded in $A$. Stimulation of these different pathways did, however, result in small changes in the shape of the postsynaptic response.

With strong shocks to either the molecular or subcellular layers, the short-latency IPSP could induce an immeasurably high increase in cell input conductance. As shown in Figure $7 A$, at the peak of an orthodromic response the membrane potential was virtually clamped at the IPSP reversal level. The IPSP was generated, at least in part, by the summation of apparent unitary events that had relatively faster rising phases than falling phases. Unitary IPSPs occasionally arose spontaneously, but they were most clearly visible when evoked orthodromically. The cell illustrated in Figure $7 B$ was recorded with a $1 \mathrm{~m}$ cesium acetatefilled microelectrode to block potassium currents and increase input resistance. A strong stimulus to the molecular layer yielded a large IPSP. When membrane potential was displaced from the resting level by injecting tonic current, discrete unitary events arose from the latter aspect of the IPSP waveform. These events were negative-going when depolarized, and positive-going when hyperpolarized, and their interpolated reversal potential was similar to that of the peak of the IPSP.

A

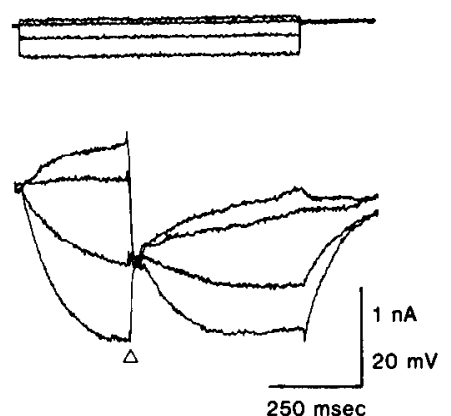

When determined for 25 pyramidal cells, the reversal potential of the short-latency IPSP was $-71.3 \pm 5.6 \mathrm{mV}$ (mean \pm SD), while the mean resting potential was $64.2 \pm 11.0 \mathrm{mV}$ (Fig. 8). Thus, most IPSPs caused a hyperpolarization when evoked at the resting level. A small minority of cells had unusually negative resting potentials, and these cells actually had short-latency IPSPs that were depolarizing. As is evident from Figure 8, IPSP reversal levels were independent of the resting potential across the sampled population.

Inhibition of pyramidal cells seemed to involve at least two pharmacologically and ionically distinct postsynaptic processes. In most cells, strong orthodromic stimuli elicited the shortlatency IPSP described above, as well as a longer-latency hyperpolarization that reversed polarity at -85 to $-95 \mathrm{mV}$ (Fig. 9). These two processes were not completely separable in time, thus complicating estimates of their reversal poentials. Nevertheless, measurements at long latencies (i.e., several hundred msec; Fig. $9 A$, arrow; $C$, triangles) consistently yielded reversal potentials about $20 \mathrm{mV}$ negative to those measured at short latencies (i.e., $10-30 \mathrm{msec}$; Fig. $9 B$, arrow; $C$, dots). The mechanistic independence of these two PSPs is also implied by the effect of intracellularly injected $\mathrm{Cl}^{-}$. As illustrated in Figure $10 \mathrm{~A}$, immediately upon impalement with a $3 \mathrm{M} \mathrm{KCl-filled} \mathrm{electrode,}$ the entire synaptic response of a pyramidal cell was hyperpolarizing. Following $10 \mathrm{~min}$ of recording, and presumed leakage of $\mathrm{Cl}^{-}$into the cell, the initial part of the IPSP reversed polarity. In this case, the inverted early phase of the IPSP exceeded the spike threshold; however, the later phase of the IPSP remained hyperpolarizing. Resting potential did not change significantly. $\mathrm{Cl}^{-}$injection did not alter the very negative reversal potential of the late IPSP, even after a prolonged period of recording, as shown in Figure 10B. These data are consistent with the hypothesis that the short-latency IPSP is mediated by an increase of $\mathrm{Cl}^{-}$conductance, while the late IPSP is not $\mathrm{Cl}^{-}$-dependent but involves a conductance increase to some other ion, perhaps $\mathrm{K}^{+}$. Similar processes have been proposed for the mammalian hippocampus (Newberry and Nicoll, 1984) and neocortex (Connors et al., 1982).

\section{Pyramidal cells: GABAergic mechanisms}

Abundant and diverse evidence suggests that GABA is the primary inhibitory neurotransmitter in the mammalian telencephalon (Krnjevic, 1984). Histochemical studies of turtle visual cortex (Blanton et al., 1985) have revealed that the stellate

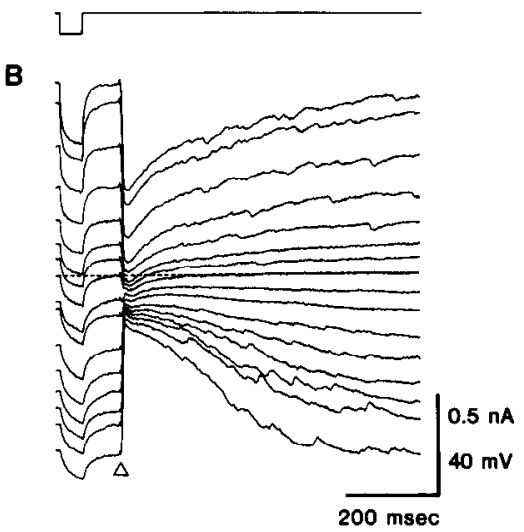

Figure 7. Characteristic synaptic response of a pyramidal cell to orthodromic stimulation. $A$, The voltage responses of a pyramidal cell (bottom traces) are shown at a series of different membrane potentials produced by a family of intracellularly applied current pulses (upper traces). A strong stimulus to the molecular layer (open triangle) produced a rapid and profound increase in the conductance of the cell that virtually clamped the membrane at the reversal potential during the peak of the IPSP. Resting potential $=-58 \mathrm{mV}$. $B$, The voltage response of a different cell to orthodromic stimulation (open triangle) is shown at a range of membrane potentials. This cell was injected with cesium to reduce potassium currents. Resting potential $(-68 \mathrm{mV})$ is indicated by the dotted lines. Long-latency unitary synaptic events can be seen during the later phase of the evoked IPSP and the polarities of these events are hyperpolarizing above, and depolarizing below the reversal potential for the evoked response. This suggests that the ionic dependence of the short-latency IPSP and the unitary synaptic potentials is the same. 


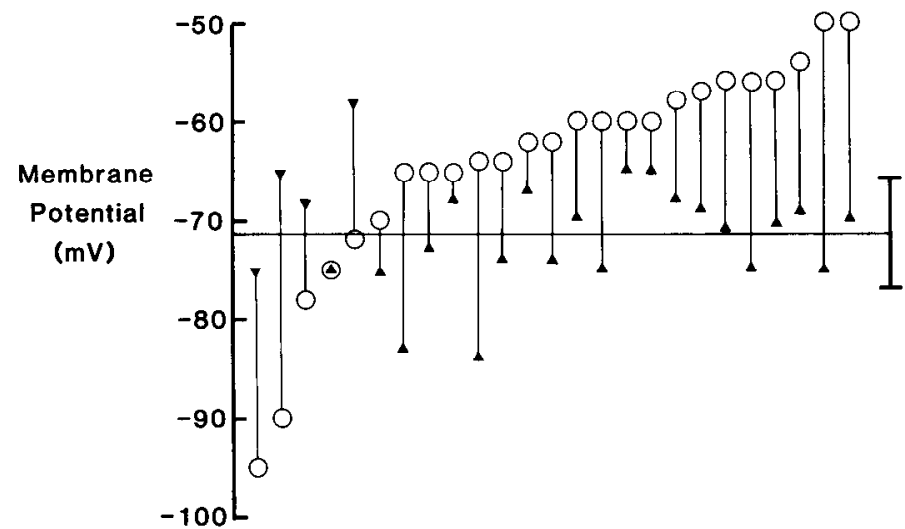

Figure 8. Plot of the resting membrane potentials (open circles) and reversal potentials (triangles) for the short-latency IPSP for 25 pyramidal cells. The line connecting each pair of points indicates data from a single cell. Although resting potentials ranged from -50 to $-95 \mathrm{mV}$, IPSP reversal potentials did not correlate with them. The horizontal line signifies the mean reversal potential \pm 1 SD for the sampled population.

cells selectively stain for GABA transaminase (the GABA degradative enzyme) and are immunoreactive for glutamic acid decarboxylase (the GABA synthesizing enzyme) and GABA itself. We have therefore begun to examine the hypothesis that pyramidal cell IPSPs are mediated, in whole or in part, by the release of GABA from stellate cells.

Focal application of GABA to the region of the soma elicited rapid hyperpolarizations concomitant with increases in membrane conductance (Fig. 11). This effect was dose-dependent. Small applications caused simple, monophasic responses. Larger doses (Fig. 11; $\geq 50 \mathrm{msec}$ ), however, usually generated a rapid hyperpolarization that subsequently diminished in amplitude despite maintenance of a large membrane conductance. In some cells, the initial hyperpolarization was actually followed by a longer-lasting depolarizing phase, which was also associated with a conductance increase. The complexity of the responses to GABA seemed to have at least two causes. First, as has been shown in hippocampal pyramidal cells of mammals (Alger and Nicoll, 1979; Andersen et al., 1980), the responses of turtle pyramidal cells to GABA were not distributed homogeneously
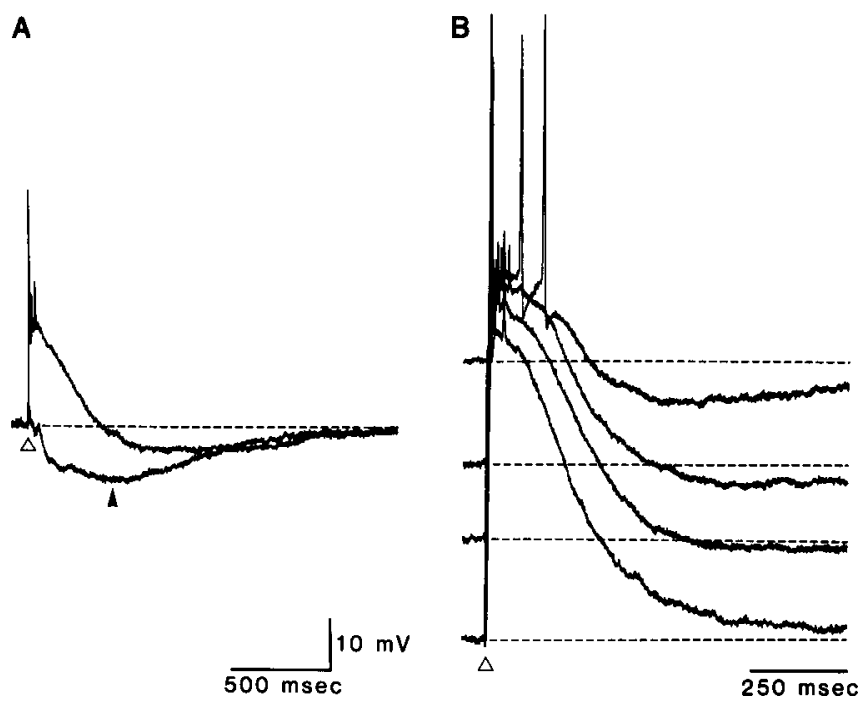

Figure 10. Effect of intracellular $\mathrm{Cl}^{-}$injection on the early and late IPSPs. $A$, The response of a pyramidal cell to molecular layer stimulation (triangle) is shown shortly after penetration (arrowhead) and following $10 \mathrm{~min}$ of $\mathrm{Cl}^{-}$injection. Injection of $\mathrm{Cl}^{-}$inverted the early phase of the hyperpolarizing response and produced a depolarization that exceeded threshold and triggered a burst of action potentials. The later hyperpolarizing phase, however, persisted. Action-potential amplitudes have been truncated by the recorder. $B$, Another cell which was injected with $\mathrm{Cl}^{-}$for $15 \mathrm{~min}$ responded to orthodromic stimulation (triangle) with a large depolarizing wave and a burst of action potentials (action-potential amplitudes were truncated by the pen recorder). Hyperpolarizing the cell to several more negative levels indicated a reversal potential of approximately $-90 \mathrm{mV}$ for the late response. These data suggest that the early IPSP is a chloride-mediated response, whereas the late IPSP is mediated by another ion.

across the neuron. For example, the cell illustrated in Figure 12 displayed a pure depolarizing response when GABA was applied to the distal basilar dendrites in the subcellular layer, near the ependymal border $(0 \mu \mathrm{m})$. Application of the same dose of GABA near the soma $(100 \mu \mathrm{m})$ yielded a strong biphasic response, and application in the intervening area $(50 \mu \mathrm{m})$ gave an intermediate response. Other cells showed different mixtures of depolarization and hyperpolarization when dendritic and so-
A
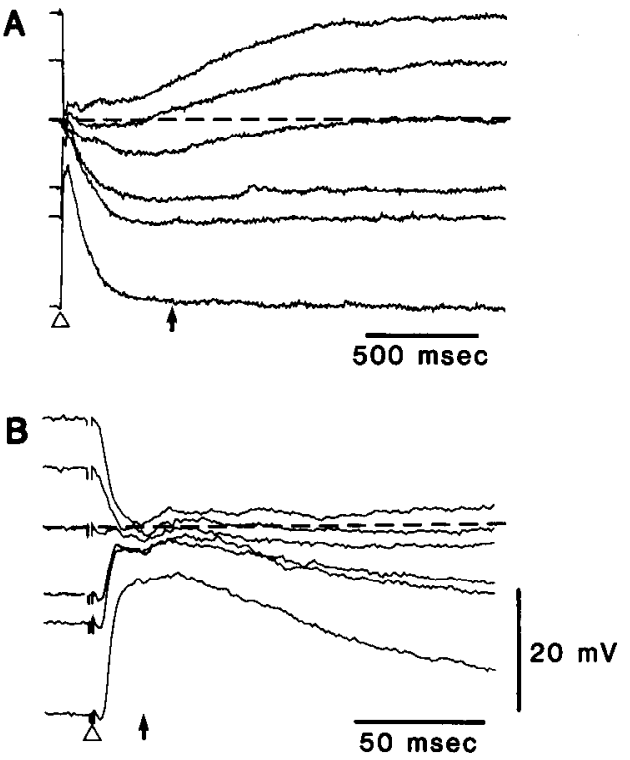

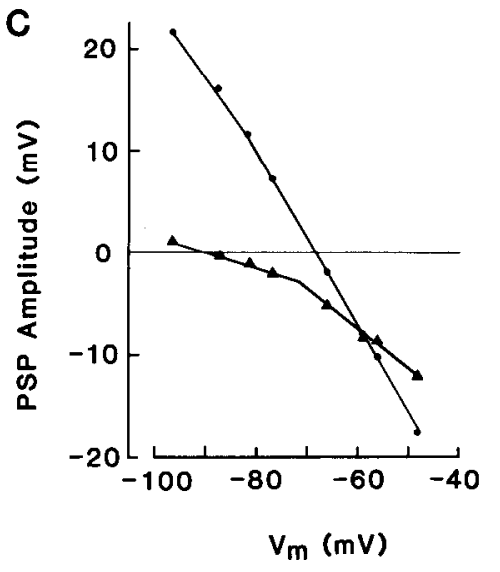

Figure 9. Strong orthodromic stimulation often produced multiphasic IPSPs in pyramidal cells. $A$ and $B$, The response of a pyramidal cell to stimulation of the subcellular zone (triangles) is shown at six different membrane potentials. Traces are shown at slow $(A)$ and fast $(B)$ time bases, and resting potential $(-66 \mathrm{mV})$ is indicated by broken lines. Arrows at latencies of $500 \mathrm{msec}(A)$ and 10 msec $(B)$ mark the points at which measurements were made. $C$, Plot of IPSP amplitude versus membrane potential $\left(V_{\mathrm{m}}\right)$ at $500 \mathrm{msec}$ latency (triangles) and $10 \mathrm{msec}$ latency (dots) from data shown in $A$ and $B$. The implied reversal potentials are $-69 \mathrm{mV}$ for the short-latency and $-89 \mathrm{mV}$ for the long-latency responses. 


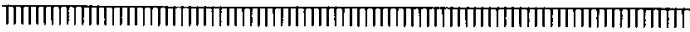

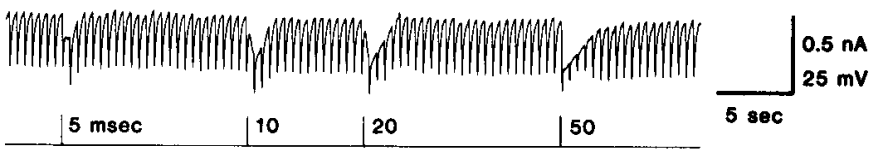

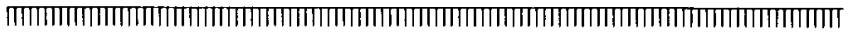

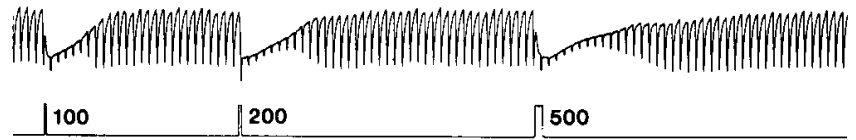

Figure 11. Response of a pyramidal cell to focal application of $5 \mathrm{~mm}$ GABA. The middle traces record the membrane voltage response; the upper traces record the applied constant current pulses; and the bottom traces mark the pressure applications of GABA ( $5 \mathrm{mM}$ ) to the perisomatic region. Increasing quantities of GABA were ejected by progressively longer-duration pressure pulses. Resting membrane potential was $-55 \mathrm{mV}$.

matic application sites were compared. Although perisomatic GABA application always yielded an initially hyperpolarizing response ( $n=15$ cells), the spatial pattern of distal applications was not consistent between cells. Thus, the complexity of pyramidal cell responses to GABA, especially in high doses, may be partly due to either the nonhomogeneous distribution of multiple GABA receptor/ionophores or regional variations in the concentration of intracellular chloride.

A second possible explanation for the complex waveform of the GABA response is that strong activation of the GABArelated ionophores may lead to a rapid transcellular redistribution of the ion(s) involved. The resultant shift in equilibrium potential would, in the face of continuously open channels, cause the membrane potential to shift in parallel. As shown in Figure 13 , this phenomenon does seem to occur. In this cell a large (1 sec; Fig. 13A) somatic GABA application generated a sharp hyperpolarization followed by a prolonged depolarization; both were accompanied by a large, maintained conductance increase. Small $(10 \mathrm{msec})$ test pulses of GABA were applied before and after the large conditioning pulse. Both the amplitude of hyperpolarization and the maximal conductance increase were depressed following the conditioning pulse, and both recovered within a similar time course (Fig. 13B). The amplitude of the hyperpolarization was, however, two to three times more greatly affected than that of the conductance increase, when each was normalized to the control level. This result implies that large GABA applications can significantly shift the equilibrium potential for the ion involved (probably $\mathrm{Cl}^{-}$), that the cell's transport systems can restore such a perturbation with a half-time of about $30 \mathrm{sec}$, and that a small amount of receptor desensitization may also occur.

One requirement for a putative neurotransmitter is that it have an identity of action with the endogenously released neurotransmitter (Werman, 1966). We compared the effect of somatically applied GABA with the evoked IPSP in pyramidal cells, and obtained data suggesting that the short-latency IPSP is a GABA-mediated response. The measurements illustrated in Figure $14 \mathrm{~A}$ were obtained from the same pyramidal cell whose synaptic responses were shown in Figure 9. The estimated reversal potential for the short-latency $(350 \mathrm{msec})$, most hyperpolarizing aspect of the GABA response was $-71 \mathrm{mV}$ (Fig. 14B, dots), a value very close to the reversal level of $-69 \mathrm{mV}$ calculated for the short-latency IPSP (Fig. $9 C$, dots). Measurements at a longer latency $(1.5 \mathrm{sec})$ implied a GABA reversal level of about $-61 \mathrm{mV}$ (Fig. 14B, triangles). In a population of $10 \mathrm{py}-$

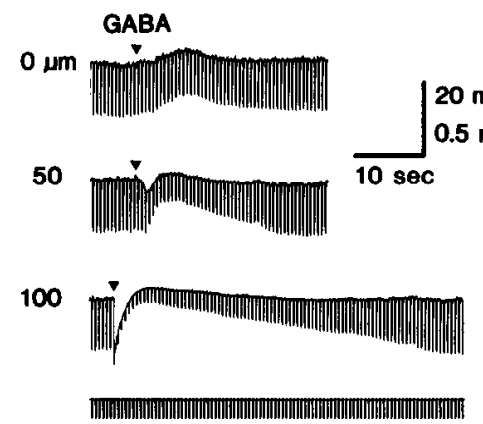

Figure 12. Dependence of the pyramidal cell, GABA, response upon application site. A GABA pipette was advanced from the ependymal layer $(0 \mu \mathrm{m})$ through the subcellular zone $(50 \mu \mathrm{m})$ to the perisomatic region $(100 \mu \mathrm{m})$. Pure depolarizing responses were evoked from sites near the distal basal dendrites, whereas GABA applied near the cell body gave hyperpolarizing-depolarizing responses. The bottom trace illustrates constant current pulses applied to the cell to monitor changes in input conductance. Resting membrane potential was $-58 \mathrm{mV}$.

ramidal cells, the mean reversal potential ( $\pm 1 \mathrm{SD}$ ) of the early hyperpolarizing response to GABA was $-69.6 \pm 6.3 \mathrm{mV}$, whereas the late positive phase reversed at $-59.3 \pm 10.3 \mathrm{mV}$. In 8 of these cells we also estimated reversal potentials of the early IPSP, and found a mean value of $-69.1 \pm 5.6 \mathrm{mV}$. When summed across cells, the mean difference between the reversal potential for the early IPSP and the early GABA reponse was $2.4 \pm 2.0 \mathrm{mV}$. We conclude that the early IPSP has the same reversal potential as the short-latency hyperpolarizing response to perisomatic GABA application.

Bicuculline is a relatively selective antagonist for the classical GABA receptor (i.e., the $\mathrm{GABA}_{\mathrm{A}}$ receptor; see Bewery et al., 1984). When applied to turtle cortex, bicuculline methiodide ( 2 $\mu \mathrm{M}$ ), a more stable analog of bicuculline, depressed the GABAinduced voltage and conductance changes in pyramidal cells (Fig. 15, $A$ and $B$, left). Bicuculline methiodide also reduced or abolished the short-latency IPSP, uncovering a net excitation (Fig. 15, $A$ and $B$, right). The longer-latency IPSP was unaffected by low doses of the antagonist; in some cases it actually increased in duration as the early excitatory response became expressed.

Higher doses of bicuculline methiodide led to paroxysmal activity in pyramidal cells, characterized by large all-or-none depolarizing waves with bursts of spikes that occurred spontaneously or following orthodromic stimuli. These burst discharges were followed by prolonged hyperpolarizations that resembled the long-latency IPSP in time course and reversal potential. Similar hyperpolarizations follow epileptic bursts in mammalian hippocampal cells (Alger and Nicoll, 1980; Hablitz, 1981; Schwartzkroin and Stafstrom, 1980), and their mechanism has been the subject of recent controversy. Our data suggest that the post-burst hyperpolarizations in turtle are at least partly synaptic in origin, and that they may be identical to the longlatency IPSP. While recording from pyramidal cells, the normal superfusate was switched to one containing $10 \mu \mathrm{M}$ bicuculline methiodide. Many cells initially generated rhythmic spontaneous negative potentials (Fig. 15C). Hyperpolarizing a cell with injected current revealed that these events had an early depolarizing phase that reversed polarity near resting potential, and a later component that reversed at the same levels as the stimulus-evoked late IPSP (i.e., -90 to $-100 \mathrm{mV}$ ). The frequency at which the events occurred was independent of membrane potential. With time, as the bicuculline concentration equilibrated, the spontaneous events developed an early depolarizing phase that eventually became the fully expressed burst of spikes (Fig. 15D). The fact that the bicuculline-insensitive hyperpolarization can occur in isolation implies that it is not dependent 
A
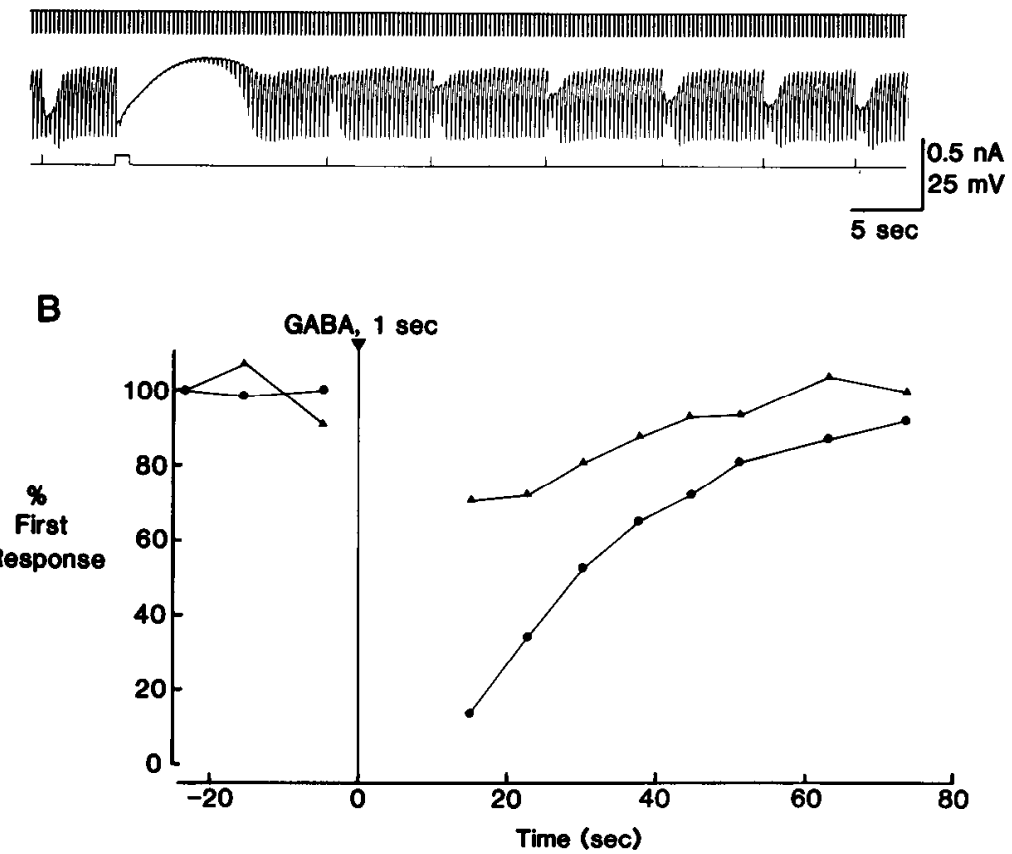

Figure 13. Effect of large GABA applications on subsequent GABA responses. $A$, Small (10 msec) test pulses of GABA applied near the soma of a pyramidal cell evoked short, hyperpolarizing responses. A large $(1 \mathrm{sec})$ conditioning pulse of GABA elicited a hyperpolarization followed by a prolonged depolarizing phase. Input conductance remained immeasurably high during both phases of the response, and then recovered to control levels. Test GABA pulses were reapplied at intervals following recovery. The first test application following the large GABA dose produced a much smaller hyperpolarization, but only a small reduction in the peak conductance change. Top trace is applied current, middle trace is voltage, and bottom trace is GABA pulse. Subsequent test applications documented a gradual return to the initial response size. $B$, Plot of test response amplitude (dots) and peak conductance increase (triangles) as a percentage of the first control response. Conditioning pulse of GABA was applied at time zero. Response amplitudes were more affected by the conditioning pulse than were the conductance increases. These results are interpreted as a consequence of a shift in the transmembrane gradient for $\mathrm{Cl}^{-}$during the response to a large GABA application.
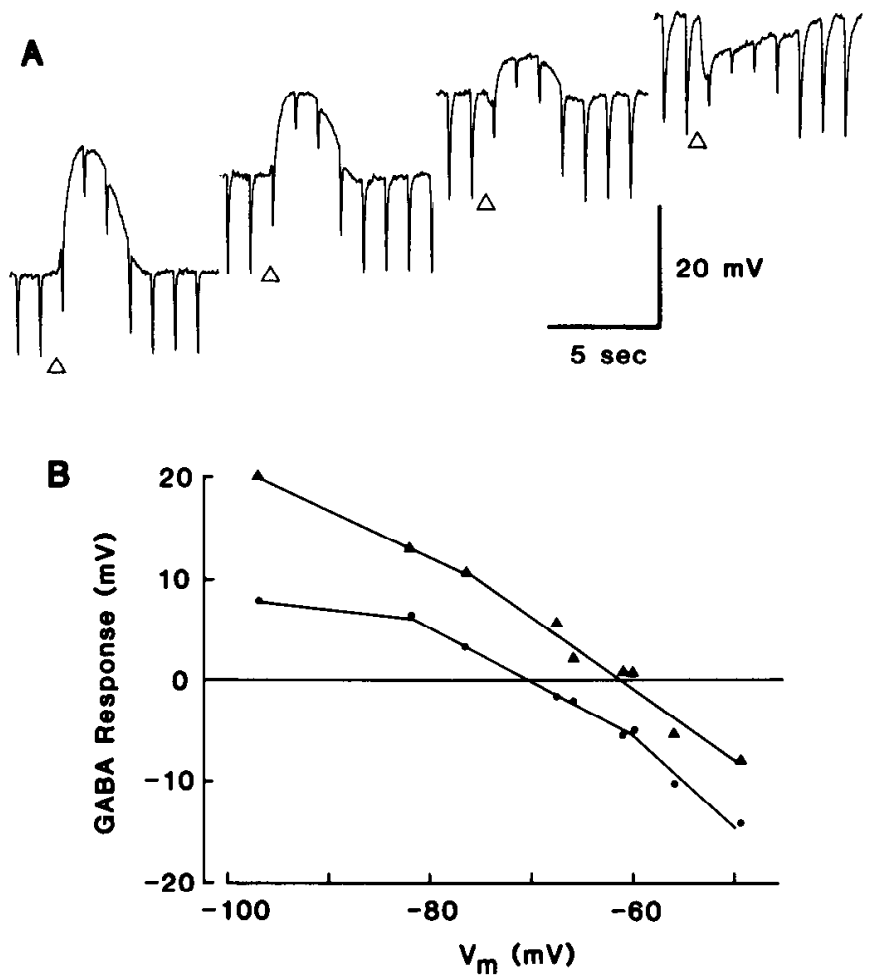

Figure 14. GABA application produced pyramidal cell responses with multiple reversal potentials. The data shown here were obtaincd from the same cell illustrated in Fig. 9. $A$, Small $(10 \mathrm{msec}, 5 \mathrm{~mm})$ pressure applications of GABA (triangles) were applied near the somatic recording site. The membrane was polarized with tonic current while small hyperpolarizing pulses were applied at $1 \mathrm{~Hz}$ to monitor input conductance. Trace at top right illustrates response at resting potential $(-61 \mathrm{mV})$, while traces to the left show successively more hyperpolarized levels. $B$, Plot of GABA response amplitude as a function of membrane potential for the samc ccll as $A$. Mcasurements were made at latencies of $350 \mathrm{msec}($ dots) and $1.5 \mathrm{sec}$ (triangles), and the implied reversal potentials were -71 and $-62 \mathrm{mV}$, respectively. 

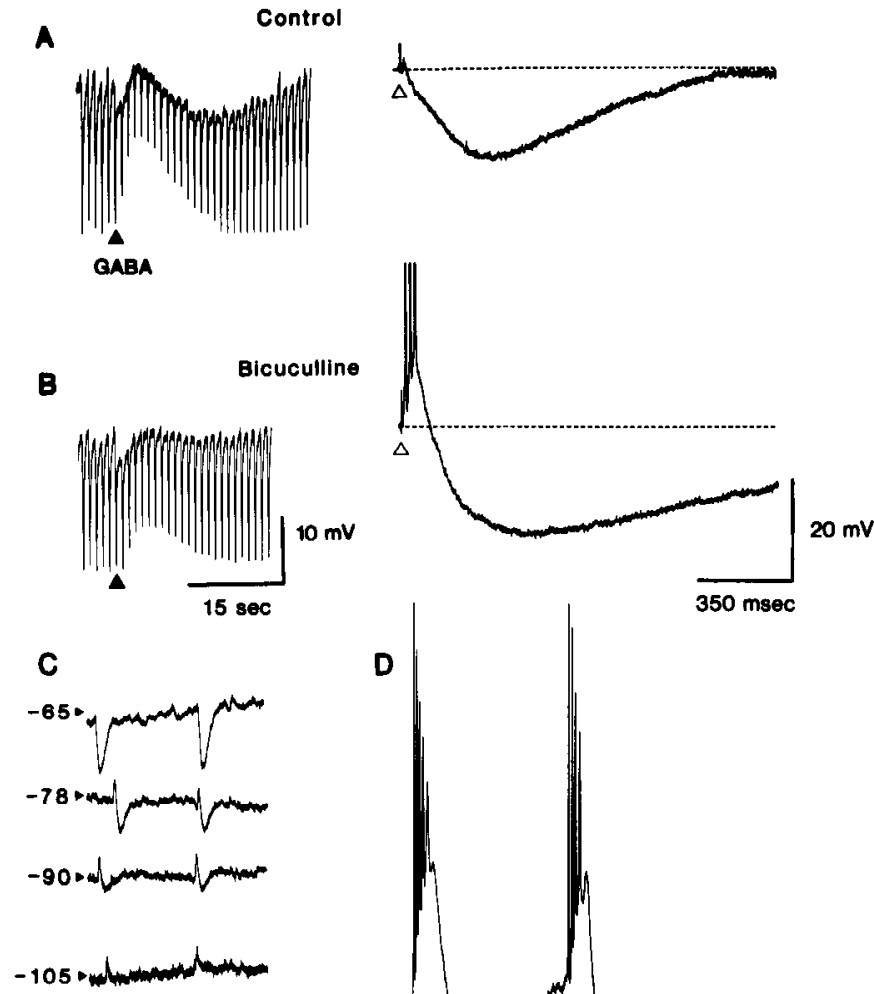

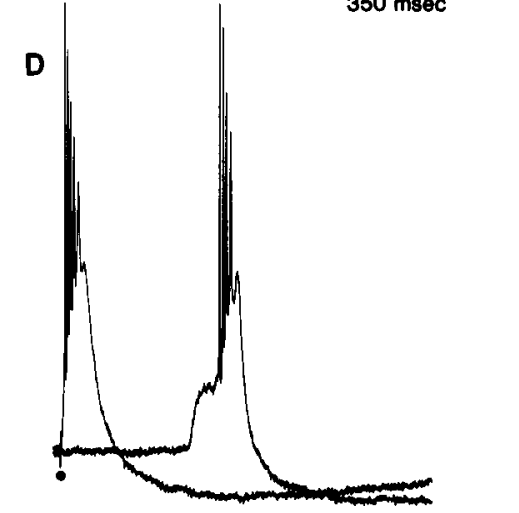

Figure 15. The effects of bicuculline methiodide on GABA responses and IPSPs of pyramidal cells. $A$, Control responses were elicited by applying perisomatic GABA pulses (left, closed triangle) and molecular layer shocks (right, open triangle). $B$, After washing in bicuculline methiodide $(2 \mu \mathrm{M})$, the GABA response amplitude and conductance increase were depressed (left). At the same time (right), the short-latency IPSP was abolished and replaced by an EPSP that triggered three spikes (tops of spikes were truncated by the pen recorder). The long-latency IPSP actually increased its hyperpolarizing amplitude. $C$, Shortly after a higher dose of bicuculline methiodide $(10 \mu \mathrm{M})$ was applied to another slice, spontaneous membrane events were recorded in pyramidal cells. These were purely hyperpolarizing at resting potential $(-65 \mathrm{mV})$. When the membrane potential was increased to the indicated levels by current injections, the early phase reversed polarity just below rest, but the later phase reversed at about -95 to $-100 \mathrm{mV}$. Altering membrane potential had no effect on the frequency of spontaneous events. $D$, After bicuculline methiodide had washed in for $30 \mathrm{~min}$, large depolarizing waves and bursts of spikes occurred, following orthodromic stimulation (dot) or spontaneously (second burst), using the same slice as in $C$. Calibrations in $B$, left, apply to all traces on left; calibrations in $B$, right, apply to all traces on right.

upon a preceding postsynaptic event, and is not likely to be based solely upon a calcium-dependent increase in potassium conductance.

\section{Activation of local synaptic circuitry}

We explored the local circuit connections in the turtle visual cortex through the use of focal applications of glutamate. Glutamate is a putative excitatory transmitter in mammalian cortex (Krnjevic, 1984), and by applying small quantities of glutamate focally in different regions of turtle cortical slabs, we were able to selectively excite small groups of neurons. Figure $16 \mathrm{~A}$ is a schematic diagram indicating the experimental approach. A pyramidal or stellate cell was impaled with a microelectrode, a miropipette filled with glutamate $(10 \mathrm{~mm})$ was positioned in either the molecular layer, pyramidal cell layer or subcellular layer, and small quantities of glutamate were ejected. The re-
A

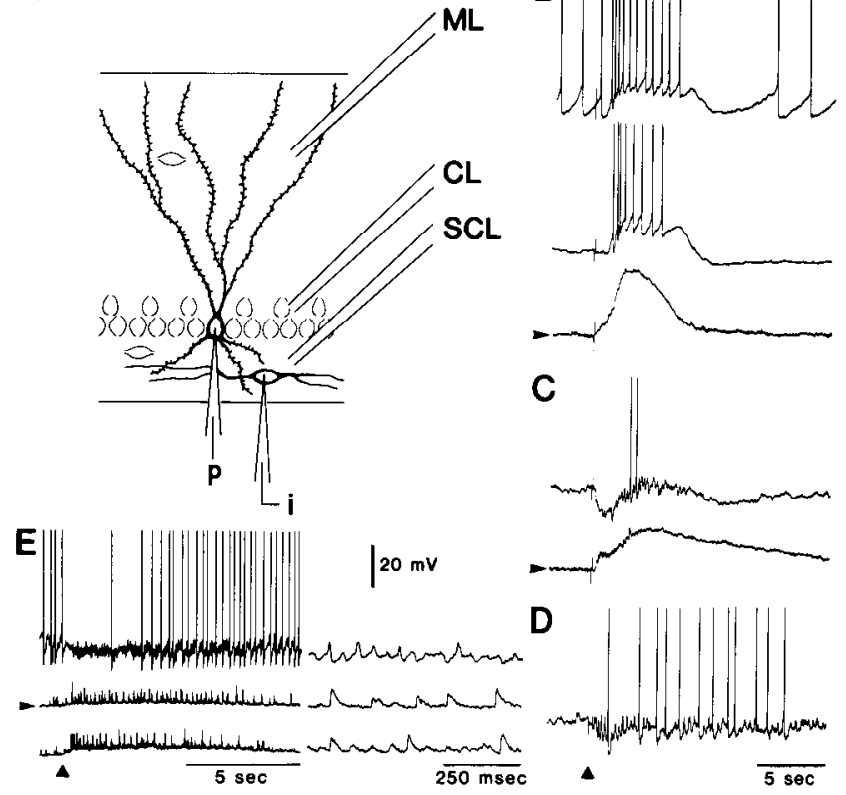

Figure 16. Selective activation of cellular elements by glutamate application. See text for details. $A$, A schematic diagram of the experimental approach. Intracellular recordings were obtained from either pyramidal cells $(p)$ or stellate cells $(i)$ during focal glutamate application to either the molecular layer $(M L)$, the cellular layer $(C L)$, or the subcellular layer $(S C L)$. $B$, Responses of a pyramidal cell to glutamate application in the region of its apical dendrites. This cell appeared to be directly excited by the glutamate application, as shown here with the cell at resting potential (arrowhead) and at two more depolarized levels. $C$, Glutamate application in the region of the cell layer, about $100 \mu \mathrm{m}$ lateral to the recording site, produced a more complicated response in this pyramidal cell, consisting of both excitatory and inhibitory synaptic events. Responses are shown at resting potential (arrow) and at a more depolarized level. $D$, Recording from a stellate cell during glutamate application in the subcellular layer lateral to the recording site. $E$, In another pyramidal cell, glutamate application to the lateral subcellular layer produced an increase in synaptic activity, leading to a net inhibition of cell firing. The synaptic barrage consisted of both excitatory and inhibitory events, as shown in the traces to the right, which represent a portion of the glutamate response transcribed at higher sweep speed. Only EPSPs are visible at the cell resting potential $(-72 \mathrm{mV}$, arrowhead), but depolarizing or hyperpolarizing the cell reveals the presence of multiple IPSPs that reverse polarity near resting level. Tops of spikes were truncated by the pen recorder in $B-E$.

sponse of neurons to glutamate varied according to the application site. Figure $16 B$ illustrates the response of a pyramidal cell to glutamate application in the region of its apical dendrites. With the membrane potential at rest, glutamate produced a depolarizing response (bottom trace). When the cell was depolarized with a current injection, glutamate triggered trains of action potentials followed by an afterhyperpolarization (Fig. $16 B$, top two traces). This effect appears to be a direct excitatory action of glutamate on the pyramidal cell membrane, since no underlying PSPs were observed. Direct excitation could also be evoked when glutamate was applied in the cellular or subcellular layers near the neuron.

Focal applications of glutamate to the pyramidal cell layer, about $100 \mu \mathrm{m}$ lateral to the recording site, produced more complicated responses in pyramidal cells. Figure $16 \mathrm{C}$ illustrates a barrage of IPSPs and EPSPs activated in this way. Under similar conditions, another pyramidal cell responded with discretely visible synaptic potentials (Fig. 16E). At resting potential (arrowhead), unitary EPSPs dominated. However, depolarizing or hyperpolarizing the cell with injected current (Fig. 16E, top and bottom traces, respectively) revealed a large number of unitary 


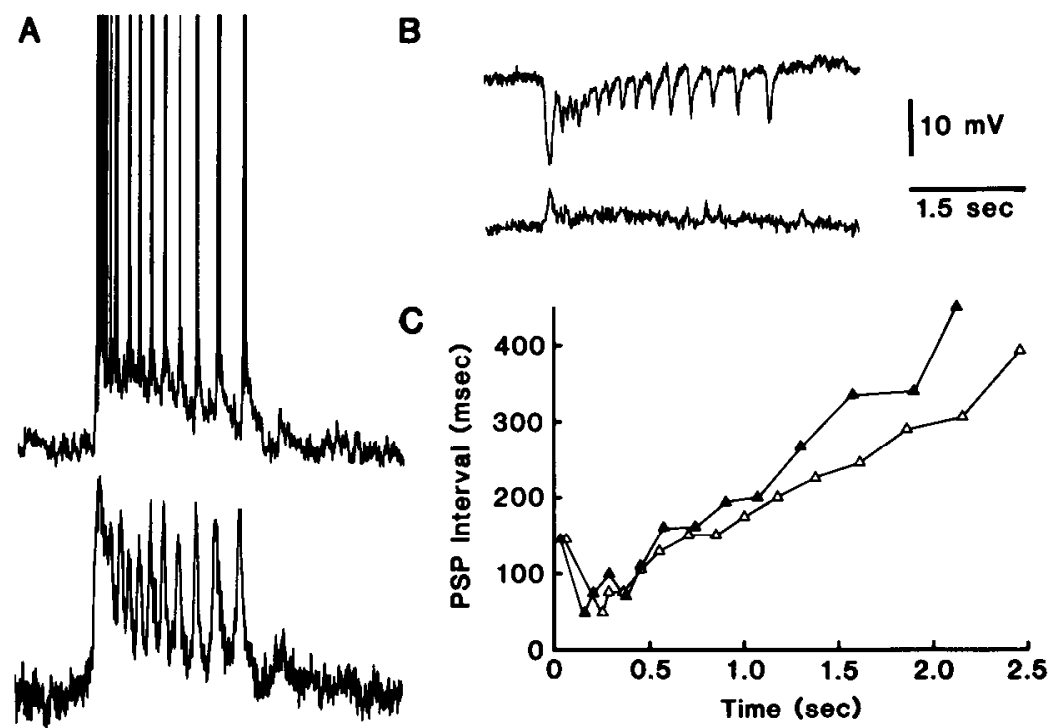

Figure 17. Glutamate-induced bursts of PSPs. $A$, Repeated local applications of glutamate led to rhythmic, repetitive bursts of action potentials in this stellate cell (spike amplitude was truncated by the pen recorder). These bursts recurred approximately every 17 sec, and the structure of each burst was nearly identical. Hyperpolarizing the cell (bottom trace) revealed a barrage of underlying EPSPs triggering the burst. $B$, Recording from a nearby pyramidal cell a few min later revealed rhythmic repetitive complexes of spontaneous IPSPs. These recurred with the same frequency as the EPSP bursts in the stellate cell. Alterations of membrane potential revealed a reversal potential for these responses of about $-70 \mathrm{mV}$. $C$, The temporal characteristics of the spontaneous PSP bursts in the stellate cell of $A$ (solid triangles) and the pyramidal cell of $B$ (open triangles) were compared by plotting the interval between EPSPs and IPSPs, respectively, as a function of latency from burst onset. The close resemblance in temporal features supports the conclusion that the bursts in both of these cell types were related to a common source.

IPSPs that reversed polarity near resting potential. Application of glutamate also led to synaptic activation of stellate neurons in the subcellular layer (Fig. 16D). The resulting shower of PSPs consisted of both excitation and inhibition, and triggered a train of action potentials. The barrage of excitatory and inhibitory activity recorded in both pyramidal and stellate cells probably arises from activation of synaptic pathways from neighboring glutamate-sensitive neurons.

Repeated applications of glutamate to a restricted portion of the dorsal cortex sometimes resulted in spontancous bursts of activity. The mechanism underlying this activity is unknown. Intracellular recordings obtained during these bursts showed that synaptic excitation of stellate cells and inhibition of pyramidal cells were temporally correlated. Figure $17 A$ shows a stellate neuron that fired bursts of action potentials lasting approximately $2 \mathrm{sec}$ and recurring with a frequency of once every 17 sec. This particular cell was not the generator for the burst, since hyperpolarizing it (bottom trace, Fig. 17A) revealed a spontaneous barrage of EPSPs underlying the spike discharge. When pyramidal cells were impaled near the same spontaneously active area, bursts of IPSPs were recorded that had a duration and frequency similar to the EPSP bursts in stellate cells. Figure $17 B$ shows a recording of such spontaneous synaptic activity in one pyramidal cell, both at resting potential and with the membrane depolarized. The reversal potential for the spontaneous IPSPs was about $-70 \mathrm{mV}$, similar to that of the short-latency IPSP evoked by electrical stimuli (cf. Fig. 8). Recordings from pyramidal neurons at distances greater than 150-250 $\mu \mathrm{m}$ from the glutamate-activated focus did not show spontaneous PSP bursts.

The similarity between spontaneous bursts in stellate and pyramidal cells is strikingly illustrated by an examination of the temporal pattern of activity in each cell type. Figure $17 C$ plots the inter-PSP interval as a function of time within the burst. Although the data were recorded sequentially, the patterns of IPSPs in the pyramidal cell and EPSPs in the stellate cell were nearly identical, strongly suggesting that their timing derived from a single source. Our interpretation is that some unrecorded cortical cell(s) was acting as a spontaneous pacemaker, and synaptically excited stellate neurons, which in turn synaptically inhibited pyramidal neurons.

\section{Discussion}

\section{Circuitry of turtle visual cortex}

Smith et al. (1980) quantitatively analyzed the distribution of degenerating thalamic terminals in the general cortex of Pseudemys scripta. Their data implied a minimal neural circuit in which thalamic volleys weakly excite the distal apical dendrites of pyramidal cells and strongly excite stellate cells. The latter are presumed to form inhibitory terminals on the dendrites and somata of pyramidal cells (Ebner and Colonnier, 1978), resulting in a prominent feedforward inhibition. Our results are entircly consistent with this model. Electrical stimulation of the subpial region, which contains the thalamocortical pathway, elicited brief, short-latency excitation in the majority of pyramidal neurons, manifested only as a small all-or-none action potential at the somatic recording site. However, the dominant effect of subpial stimulation was large and long-lasting inhibition of pyramidal cells. Stellate cells, on the other hand, were strongly excited under the same conditions. The timing of these synaptic events is consistent with feedforward mediation of the IPSPs, though recurrent components may also contribute.

Strong stimuli to the molecular layer evoked two mechanistically distinct, but temporally overlapping, IPSPs in pyramidal cells. The early, high-conductance phase of inhibition is probably mediated by GABA via a classic $\mathrm{GABA}_{\mathrm{A}}$ receptor coupled to a $\mathrm{Cl}^{-}$-selective ionophore (Bowery et al., 1984). The evidence for this hypothesis includes the following factors: (a) Somatic application of GABA can mimic the magnitude and reversal potential of the conductance evoked by the IPSP; (b) the early IPSP and the response to GABA are antagonized by bicuculline methiodide; (c) $\mathrm{Cl}^{-}$injection can shift the reversal potential for the early IPSP; and (d) most or all stellate cells stain positively for GABAergic histochemical markers (Blanton et al., 1985). 


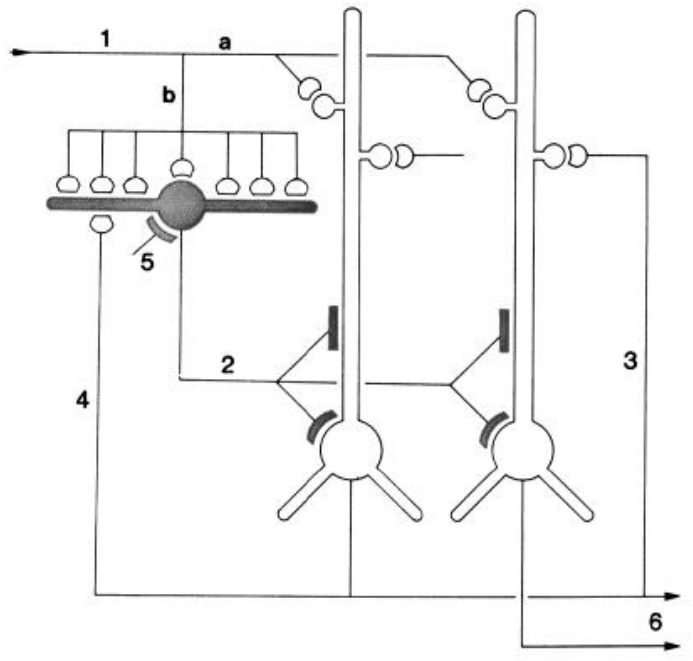

Figure 18. Schematic diagram of the principal intracortical connections of the turtle visual cortex based on neuroanatomical data (Smith et al., 1980) and the physiological observations reported here. Thalamocortical afferent volleys (l) provide direct excitation of pyramidal cell dendrites $(a)$ and also powerfully excite inhibitory stellate cells $(b)$. Feedforward inhibition is mediated by stellate cell-pyramidal cell contact (2). Local pathways also mediate reciprocal excitation between pyramidal cells (3) as well as feedback inhibition through pyramidal cell-stellate cell contact (4). There is also physiological support for inhibition of stellate interneurons (5), presumably arising from stellate cell-stellate cell contact. The pyramidal cells provide output from the cortex (6) by way of axons coursing primarily in the subcellular zone.

The intracortical stellate cells are likely to be the major, if not the only, source for this GABA-mediated inhibition. Local glutamate applications probably excite only soma-dendritic membranes, not axons (Christian and Dudek, 1984), and the IPSPs observed in pyramidal cells under these conditions have the same reversal potentials as the early IPSPs evoked by subpial electrical stimuli. The source and mechanism of the longerlatency IPSP are unknown; however, the very negative reversal potential suggests that the longer-latency IPSP is associated with a $\mathrm{K}^{+}$conductance increase, and its insensitivity to bicuculline methiodide suggests that it is not mediated by $\mathrm{GABA}_{\mathrm{A}}$ receptors.

Our physiological data encourage additions to the circuitry, as proposed by Smith et al. (1980). Electrical stimulation of the subcellular layer, which contains efferent fibers of the pyramidal cells, elicits stellate cell excitation similar to that evoked from the subpial region, and concurrent pyramidal cell inhibition. Although it is possible that these effects are mediated exclusively via incoming fibers in the subcellular layer, thus constituting a second and distinct feedforward inhibitory circuit, a simpler explanation is that recurrent collaterals of pyramidal cells impinge on stellate cells, which then feed back upon pyramids. The requisite collaterals have been seen in Golgi-stained preparations (Desan, 1984; Ramon, 1896). The spontaneous IPSPs seen in pyramidal cells during glutamate-induced bursting are also consistent with this hypothesis. Subcellular stimulation also results in short-latency excitation in pyramidal cells, although this is often masked by inhibition. It is likely that some of these EPSPs result from a feedback excitation which, in the apparent absence of any excitatory interneurons, would necessarily arise from direct pyramid-to-pyramid synaptic connections. The existence of such reciprocal contacts is also supported by the highly synchronized epileptiform bursting observed when turtle cortex is disinhibited with bicuculline. Reciprocal excitatory circuits can also explain the barrage of EPSPs recorded in pyramidal cells when neighboring pyramidal cells are excited by glutamate application.
In a recent series of experiments, intracellular cortical responses to visual stimuli were obtained in a preparation in which the intact turtle visual system was isolated in vitro (Kriegstein, 1985). Light flashes produced a brief, early EPSP that was followed by longer-lasting IPSPs with a reversal potential of about $-70 \mathrm{mV}$. Thus, the physiological responses closely resembled the response to electrical stimulation of afferent fibers in the isolated cortical slab.

Figure 18 gives a simple scheme of the circuitry in turtle general cortex. It incorporates the basic elements of the model of Smith et al. (1980), which were inferred from morphological data. Our additional conclusions, derived from physiological observations and outlined above, have been added. The results of field-potential studies following stimulation of various parts of the molecular layer (Fig. 4) further imply that nonthalamic afferent systems contact the apical dendrites of pyramidal cells all along their length. The origin of these excitatory fibers is unknown, but they probably include both subcortical and associational sources.

\section{Comparison with other cortical systems}

The general synaptic organization of turtle general cortex shows striking similarities with those of other cerebral cortical structures, including the pyriform cortex, hippocampus, and neocortex of several well-studied mammalian species (Shepherd, 1979). Each cortex has a principal cell type (or group of subtypes) that features prominent, spinous apical dendrites, and one or more types of sparsely spinous, GABA-utilizing interneuron. Similarities exist for both the general plan of local circuitry and the physiology of the synapses themselves. The uniqueness of each cortex is, of course, specified by many differences of organization. A comparison of these properties between and within species may yield clues about the principles of cortical function and its evolution.

In turtle cortex, thalamic afferents directly excite both pyramidal cells and inhibitory stellate cells; this results in a prominent feedforward inhibition. Recent evidence suggests that this occurs in mammalian cortices also. In the pyriform cortex of the opossum (Haberly and Bower, 1984), but perhaps not the rabbit (Satou et al., 1983), axons of the lateral olfactory tract seem to excite principal cells as well as inhibitory interneurons. There is convincing evidence that afferent impulses of the CA1 region in the cat and rat hippocampus directly activate both pyramidal neurons and feedforward GABAergic interneurons (Alger and Nicoll, 1982; Ashwood et al., 1984; Purpura et al., 1968). In the neocortex, physiological investigations have yielded few unambiguous clues about the nature of local inhibitory circuitry. Nevertheless, anatomical studies in the rat and cat (Globus and Scheibel, 1967; White, 1978) demonstrate that specific thalamocortical axons terminate on both pyramidal cell dendrites and the spine-free dendrites of cells presumed to be inhibitory, based on GAD immunohistochemistry (Ribak, 1978). Presumed inhibitory cells then make direct connections with pyramidal cells (De Felipe and Fairen, 1982; Peters and Fairen, 1978; Peters and Proskauer, 1980; Somogyi et al., 1982), yielding the morphological requirements for feedforward inhibition. When afferents are electrically stimulated, the timing of excitation in some identified interneurons (Martin et al., 1983) and the IPSP latency in presumed pyramidal cells (Toyama et al., 1974) are consistent with the feedforward scheme. Principal neurons in most cortical areas respond to afferent stimulation with an excitatory/inhibitory sequence of synaptic activation (Purpura, 1967). The role of inhibition in the cortex may be to enhance spatial contrast (Mountcastle, 1978) and to define features of the receptive field, such as directional specificity, orientation, and end-inhibition in mammalian visual cortex (Sillito, 1984). Thus, it is likely that a parallel activation of principal cells and interneurons by afferent input, followed by inhibition 
of the principal cells, is a very common feature of cortical organization.

Feedback (or recurrent) inhibitory circuits have long been recognized in mammalian cortical structures. In pyriform cortex of cat, opossum, and rabbit, they may account for most of the IPSPs evoked by afferent excitation (Biedenbach and Stevens, 1969; Haberly and Shepherd, 1973; Satou et al., 1983). There is evidence for more than one type of inhibitory interneuron that mediates feedback IPSPs in cat and guinea pig hippocampus (Andersen et al., 1964; Kandel et al., 1961; Knowles and Schwartzkroin, 1981). Recurrent inhibition in neocortex was demonstrated physiologically by Phillips (1959) and Stefanis and Jasper (1964). Although a variety of suspected inhibitory interneurons have been described morphologically in neocortex (e.g., Feldman and Peters, 1978), the identity of the cell type(s) mediating recurrent inhibition is unknown.

We have presented indirect evidence for reciprocal excitation between turtle pyramidal cells. This is also a very common, if not completely general, feature of mammalian cortical circuitry. It has been proposed for opossum pyriform cortex (Haberly and Bower, 1984), based on the timing of evoked EPSPs and the morphology of axon collaterals. Simultaneous recordings from some pairs of pyramidal cells in the CA3-CA4 area of rat hippocampus unequivocally demonstrated monosynaptic excitation (MacVicar and Dudek, 1980); similar experiments in the CA1 area of guinea pig, however, did not (Knowles and Schwartzkroin, 1981). Physiological experiments in neocortex are quite consistent with an important role for recurrent excitation, at least in pyramidal tract cells (Phillips, 1959; Takahashi et al., 1967). Anatomical data suggest a much more general role. Lorente de No (1938) commented on the abundance and ubiquity of recurrent axon collaterals emanating from pyramidal cells (cf. Lund and Boothe, 1975). Ultrastructurally, the vast majority of terminals from pyramidal cell axons make asymmetric (and thus presumably excitatory) contacts onto spines (Colonnier, 1968; Peters and Kaiserman-Abramof, 1969); further, the vast majority of dendritic spines outside of layer IV belong to pyramidal cells. Therefore, it is highly probable, and most contemporary schemes of neocortical circuitry assume (Gilbert and Wiesel, 1981; Mountcastle, 1978; Szentagothai, 1978), that pyramidal neurons make recurrent reciprocal excitatory synapses in abundance.

Our proposed cortical circuit of the turtle visual system, which appears to embody the essential features common to cortical function, also provides the necessary substrate for epilepsy. One conscquence of a system with abundant reciprocal excitatory connections held in check by recurrent inhibition is the risk of epileptiform activity if the balance of excitation or inhibition is shifted. For example, in these experiments, spontaneous repetitive discharges developed when GABAergic inhibition was depressed by bicuculline, and also following repcated focal cxcitation by glutamate. Many explanations of cortical epileptogenesis invoke strong reciprocal excitatory synaptic mechanisms to account for neuronal synchronization at the site of discharge initiation (e.g., Connors and Gutnick, 1984; Ebersole and Chatt, 1984; Traub and Wong, 1982). Another prominent feature of focal neocortical epilepsy is surround inhibition, in which a local paroxysmal discharge evokes, through laterally projecting pathways of recurrent inhibition, sets of synchronous IPSPs on surrounding neurons (Prince and Wilder, 1967). A similar phenomenon seems to occur in the turtle (Fig. 15). Thus, the most primitive and highly conserved features of normal cortical circuitry also provide the basis for focal epilepsy.

Similarities of general synaptic connectivity do not necessarily imply similarities of specific synaptic function. At present, detailed comparisons across species are not possible. For example, the identity of the excitatory transmitter released by cortical pyramidal cells is not well defined for any system. Nevertheless, the known similarities of synaptic physiology in various cortical structures are more striking than the differences. Bicucullinesensitive responses of pyramidal cells to GABA are quite similar in the turtle cortex (this study), mammalian hippocampus (Alger and Nicoll, 1979; Andersen et al., 1980), and rat neocortex (Connors and Malenka, 1985). There are currently no reports of multiple types of GABA responses in olfactory cortical neurons (cf. Brown and Scholfield, 1979); however, this absence may simply be due to oversight. The long-duration, presumably $\mathrm{K}^{+}$-mediated, IPSPs observed in turtle pyramidal cells closely resemble a set of analogous IPSPs in rabbit pyriform cortex (Satou et al., 1982), rat hippocampus (Newberry and Nicoll, 1984), and guinea pig neocortex (Connors et al., 1982).

All living vertebrates have a pallium (or telencephalic roof), with lateral, medial and dorsal subdivisions, which strongly suggests that this is a homologous feature (i.e., derived from a common ancestral structure; Northcutt, 1981). The specific characteristics of the pallium in each species, such as regional variations in size, local differentiation, number and variety of interneurons, and specificity of ascending and descending pathways, may vary widely. Similarities of specific features across species may represent examples of either homology or homoplasy (i.e., independent evolution); in the case of individual pallial structures, deciding between these alternatives is at present very difficult (Northcutt, 1981; Ulinski, 1983). As outlined above, the general plans for the local synaptic circuitry of turtle dorsal cortex and mammalian telencephalic cortices have some basic similarities. Two evolutionary possibilities exist. The principles of local synaptic organization may be homologous among telencephalic cortices, having evolved in an early stem vertebrate in response to the selective pressures shaping the forebrain. Alternatively, similar local organizations may have arisen separately and evolved in parallel, suggesting that they represent analogous solutions to common functional necessities. A wider comparative survey of the cellular physiology of the telencephalic cortex may help to decide between these two hypotheses.

\section{References}

Alger, B. E., and R. A. Nicoll (1979) GABA-mediated biphasic inhibitory response in hippocampus. Nature $281: 315-317$.

Alger, B. E., and R. A. Nicoll (1980) The epileptiform burst after hyperpolarization: A calcium-dependent potassium potential in hippocampal pyramidal cells. Science $210: 1122-1124$.

Alger, B. E., and R. A. Nicoll (1982) Feed-forward dendritic inhibition in rat hippocampal pyramidal cells studied in vitro. J. Physiol. (Lond.) 328: 105-123.

Andersen, P., R. Dingledine, L. Gjerstad, I. A. Langmoen, and A. Mosfeldt-Laursen (1980) Two different responses of hippocampal pyramidal cells to application of gamma-aminobutyric acid. J. Physiol. (Lond.) 305: 279-296.

Andersen, P., J. C. Eccles, and Y. Loyning (1964) Pathways of postsynaptic inhibition in the hippocampus. J. Neurophysiol. 27: 608619.

Andersen, P., H. Silfvenius, S. H. Sundberg, and O. Sveen (1980) A comparison of distal and proximal dendritic synapses on CAl pyramids in guinea pig hippocampal slices in vitro. J. Physiol. (Lond.) 307: 273-299.

Ashwood, T. J., B. Lancaster, and H. V. Wheal (1984) In vivo and in vitro studies on putative interneurones in the rat hippocampus: Possible mediators of feedforward inhibition. Brain Res. 293: 279-291.

Atwood, H. L., F. Lang, and W. Morin (1972) Synaptic vesicles: Selective depletion in excitatory and inhibitory axons. Science 126 . 1353-1355.

Belekhova, M. G. (1965) Post-tetanic potentiation and recruitment in the cerebral cortex of turtles. Zh. Vyssh. Nerv. Dezat. I.P. Pavlova 17: 513-522.

Biedenbach, M. A., and C. F. Stevens (1969) Synaptic organization of cat olfactory cortex as revealed by intracellular recording. J. Neurophysiol. 32: 204-214.

Blanton, M., J. Shen, and A. R. Kriegstein (1985) Stellate neurons in 
the turtle dorsal cortex contain $\gamma$-aminobutyric acid and its synthetic enzyme. Soc. Neurosci. Abstr. 11: 802.

Bowery, N. G., G. W. Price, A. L. Hudson, D. R. Hill, G. P. Wilkin, and M. J. Turnbull (1984) GABA receptor multiplicity: Visualization of different receptor types in the mammalian CNS. Neuropharmacol. 23: 219-231.

Brown, D. A., and C. N. Scholfield (1979) Depolarization of neurones in the isolated olfactory cortex of the guinea pig by $\gamma$-aminobutyric acid. Br. J. Pharmacol. 65: 339-345.

Christian, E. P., and F. E. Dudek (1984) Glutamate microapplication as a physiological method to study local neuronal circuits in hippocampal circuits. Soc. Neurosci. Abstr. 10: 1076.

Colonnier, U. (1968) Synaptic patterns on different cell types in the different laminae of the cat visual cortex. Brain Res. 9: 268-287.

Connors, B. W., and M. J. Gutnick (1984) Cellular mechanisms of neocortical epileptogenesis in an acute experimental model. In Electrophysiology of Epilepsy, P. Schwartzkroin and H. Wheal, eds., pp. 79-105, Academic, New York.

Connors, B. W., and A. R. Kriegstein (1986) Cellular physiology of the turtle visual cortex: Distinctive properties of pyramidal and stellate neurons. J. Neurosci. 6: 164-177.

Connors, B. W., and R. C. Malenka (1985) Neocortical pyramidal cells: GABA ${ }_{A}$ and $\mathrm{GABA}_{B}$ mediated responses and two types of IPSP. Soc. Neurosci. Abstr. 11:7.

Connors, B. W., M. J. Gutnick, and D. A. Prince (1982) Electrophysiological properties of neocortical neurons in vitro. J. Neurophysiol. 48: 1302-1320.

Connors, B. W., A. R. Kriegstein, and B. R. Ransom (1983) Cellular physiology of the turtle cortex. Soc. Neurosci. Abstr. 9: 679.

De Felipe, J., and A. Fairen (1982) A type of basket cell in superficial layers of the cat visual cortex. A Golgi-electronmicroscope study. Brain Res. 244: 9-16.

Desan, P. H. (1984) The organization of the cerebral cortex of the pond turtle, Pseudemys scripta elegans. Ph.D. dissertation, Harvard University, Cambridge, MA.

Ebersole, J. S., and A. Chatt (1984) Laminar interactions during neocortical epileptogenesis. Brain Res. 298: 253-271.

Ebner, F. F., and M. Colonnier (1975) Synaptic patterns in the visual cortex of turtle. J. Comp. Neurol. 160: 51-79.

Ebner, F. F., and M. Colonnier (1978) Quantitative studies of synapses in turtle visual cortex. J. Comp. Neurol. 179: 263-276.

Feldman, M. L., and A. Peters (1978) The forms of non-pyramidal neurons in rat visual cortex. J. Comp. Neurol. 179: 761-794.

Gilbert, C. D., and T. N. Wiesel (1981) Laminar specialization and intracortical connections in cat primary visual cortex. In The Organization of the Cerebral Cortex, F. O. Schmitt, F. G. Worden, G. Adelman, and S. G. Dennis, eds., pp. 163-194, MIT Press, Cambridge, MA.

Globus, A., and A. B. Scheibel (1967) Synaptic loci on visual cortical neurones of the rabbit. The specific afferent radiation. Exp. Neurol. 18: 116-131.

Haberly, L. B., and J. M. Bower (1984) Analysis of association fiber system in pyriform cortex with intracellular recording and staining techniques. J. Neurophysiol. 51: 90-112.

Haberly, L. B., and G. M. Shepherd (1973) Current-density analysis of summed evoked potentials in opossum prepyriform cortex. J. Neurophysiol. 36: 789-802.

Hablitz, J. J. (1981) Effects of intracellular injections of chloride and EGTA on postepileptiform-burst hyperpolarizations in hippocampal neurons. Neurosci. Lett. 22: 159-163.

Hall, W. C., and F. F. Ebner (1970) Thalamo-telencephalic projections in the turtle Pseudemys scripta. J. Comp. Neurol. 140: 101-122.

Hall, J. A., R. E. Foster, F. F. Ebner, and W. C. Hall (1977) Visual cortex in a reptile, the turtle (Pseudemys scripta and Chrysemys picta). Brain Res. 130: 197-216.

Hohmann, C. F., P. T. Carroll, and F. F. Ebner (1983) Acetylcholine levels and choline acetyltransferase activity in turtle cortex. Brain Res. 258: 120-122.

Kandel, E. R., W. A. Spencer, and F. J. Brinley (1961) Electrophysiology of hippocampal neurons. I. Sequential invasion and synaptic organization. J. Neurophysiol. 24: 225-242.

Karamian, A. I., N. P. Vesselkin, M. G. Belekhova, and T. M. Zagorulko (1966) Electrophysiological characteristics of tectal and thalamocortical divisions of the visual system in lower vertebrates. J. Comp. Neurol. 127: 559-576.

Knowles, W. D., and P. A. Schwartzkroin (1981) Local circuit synaptic interactions in hippocampal brain slices. J. Neurosci. 1: 318-322.
Kriegstein, A. R. (1985) An intact vertebrate visual system in vitro: Visually evoked pyramidal cell responses in turtle cortex. Soc. Neurosci. Abstr. 11: 1014.

Kriegstein, A. R., and B. W. Connors (1984) Synaptic interactions and neurotransmitter responses of turtle visual cortex. Soc. Neurosci. Abstr. 10: 659 .

Krnjevic, K. (1984) Neurotransmitters in cerebral cortex. A general account. In Cerebral Cortex, Vol. 2. Functional Properties of Cortical Cells, E. G. Jones and A. Peters, eds., pp. 39-61, Plenum, New York.

Lorente de No, R. (1938) The cerebral cortex: Architecture, intracortical connections and motor projections. In Physiology of the Nervous System, J. F. Fulton, ed., pp. 291-339, Oxford, Oxford.

Lund, J. S., and R. G. Boothe (1975) Interlaminar connections and pyramidal neuron organization in the visual cortex, area 17, of the Macaque monkey. J. Comp. Neurol. 159: 305-334.

MacVicar, B. A., and F. E. Dudek (1980) Local synaptic circuits in rat hippocampus: Interactions between pyramidal cells. Brain Res. 184: 220-223.

Martin, A. R. (1977) Junctional transmission. II. Presynaptic mechanisms. In Handbook of Physiology, Section 1: The Nervous System, Vol. 1. Cellular Biology of Neurons, Part 1, E. R. Kandel, ed., chap. 10, pp. 329-356, American Physiological Society, Bethesda, MD.

Martin, K. A. C., P. Somogyi, and D. Whitteridge (1983) Physiological morphological properties of identified basket cells in the cat's visual cortex. Exp. Brain Res. 50: 193-200.

Mazurskaya, P. Z., T. V. Davydova, and G. D. Smirnov (1966) Functional organization of exteroceptive projections in the forebrain of the turtle. Fiziol. Zh. SSSR 52: 109-117.

Mitzdorf, U. (1985) Current source-density method and application in cat cerebral cortex: Investigation of evoked potentials and EEG phenomena. Physiol. Rev. 65: 37-100.

Mountcastle, V. B. (1978) An organizing principle for cerebral function: The unit module and the distributed system. In The Mindful Brain. Cortical Organization and the Group-Selective Theory of Higher Brain Function, G. M. Edelman and V. B. Mountcastle, eds., pp. 750, MIT, Cambridge, MA.

Newberry, N. R., and R. A. Nicoll (1984) A bicuculline-resistance inhibitory post-synaptic potential in rat hippocampal pyramidal cells in vitro. J. Physiol. 348: 239-254.

Northcutt, R. G. (1981) Evolution of the telencephalon in non-mammals. Ann. Rev. Neurosci. 4: 301-350.

Orrego, F., and D. Lisenby (1962) The reptilian forebrain. IV. Electrical activity in the turtle cortex. Arch. Ital. Biol. 100: 17-30.

Ouimet, C. C., and F. F. Ebner (1981) Extrathalamic inputs to the cerebral cortex of the turtle Pseudemys scripta. Anat. Rec. 199: 189A.

Parent, A., and D. Poitras (1974) The origin and distribution of catecholaminergic axon terminals in the cerebral cortex of the turtle (Chrysemys picta). Brain Res. 78: 345-358.

Peters, A., and A. Fairen (1978) Smooth and sparsely-spined stellate cells in the visual cortex of the rat: A study using a combined Golgielectron microscope technique. J. Comp. Neurol. 181: 129-172.

Peters, A., and I. R. Kaiserman-Abramof (1969) The small pyramidal neuron of the rat cerebral cortex. The synapses upon dendritic spines. Z. Zellforsch. 100: 487-506.

Peters, A., and C. C. Proskauer (1980) Synaptic relations between a multipolar stellate cell and a pyramidal neuron in the rat visual cortex. A combined Golgi-electronmicroscope study. J. Neurocytol. 9: $163-183$.

Phillips, C. G. (1959) Actions of antidromic pyramidal volleys on single Betz cells in the cat. Q. J. Exp. Biol. 44: 1-25.

Prince, D. A., and B. J. Wilder (1967) Control mechanisms in cortical epileptogenic foci: "Surround" inhibition. Arch. Neurol. 16: 194202.

Purpura, D. P. (1967) Comparative physiology of dendrites. In The Neurosciences: A Study Program, G. C. Quaton, T. Mclnechuck, and F. O. Schmitt, eds., pp. 372-392, Rockefeller, New York.

Purpura, D. P., S. Prelevic, and M. Santini (1968) Postsynaptic potentials and spike variations in feline hippocampus during postnatal ontogenesis. Exp. Neurol. 22: 408-417.

Ramon, P. (1896) El encefalo de los reptiles. (1896) Estructura del encefalo del camaleon. Rev. Trim. Micrograf. 1 (as cited in Ramon y Cajal, 1911).

Ramon y Cajal, S. (1911) Histologie du Systeme Nervoux de l'Homme et des Vertebres, Maloine, Paris.

Ribak, C. E. (1978) Aspinous and sparsely-spinous stellate neurons in the visual cortex of rats contain glutamic acid decarboxylase. $J$. Neurocytol. 7: 461-478. 
Satou, M., K. Mori, Y. Tazawa, and S. F. Takagi (1982) Two types of postsynaptic inhibition in pyriform cortex of the rabbit: Fast and slow inhibitory postsynaptic potentials. J. Neurophysiol. 48: 11421156.

Satou, M., K. Mori, Y. Tazawa, and S. F. Takagi (1983) Interneurons mediating fast postsynaptic inhibition in pyriform cortex of the rabbit. J. Neurophysiol. 50: 89-101.

Schwartzkroin, P. A., and C. E. Stafstrom (1980) Effects of EGTA on the calcium activated afterhyperpolarization in hippocampal CA3 pyramidal cells. Science 210:1125-1126.

Shepherd, G. M. (1979) The Synaptic Organization of the Brain, Oxford, Oxford.

Sillito, A. M. (1984) Functional considerations of the operation of GABAergic inhibitory processes in the visual cortex. In Cerebral Cortex, Vol. 2, Functional Properties of Cortical Cells, E. G. Jones and A. Peters, eds., pp. 91-117, Plenum, New York.

Smith, L. M., F. F. Ebner, and M. Colonnier (1980) The thalamocortical projection in Pseudemys turtles: A quantitative electronmicroscopic study. J. Comp. Neurol. 190: 445-461.

Somogyi, P., T. F. Freund, and A. Cowey (1982) The axo-axonic interneuron in the cerebral cortex of the rat, cat and monkey. Neuroscience $7: 2577-2607$.
Stefanis, C. N., and H. H. Jasper (1964) Recurrent collateral inhibition in pyramidal tract neurons. J. Neurophysiol. 27: 855-877.

Szentagothai, J. (1978) The neuron network of the cerebral cortex: A functional interpretation. Proc. R. Soc. (Lond.) [Biol.] 201: 219-248.

Takahashi, K., K. Kubota, and M. Uno (1967) Recurrent facilitation in cat pyramidal tract cells. J. Neurophysiol. 30: 22-34.

Toyama, K., K. Matsunami, T. Ohno, and S. Tokashiki (1974) An intracellular study of neuronal organization in the visual cortex. Exp. Brain Res. 21: 45-66.

Traub, R. D., and R. K. S. Wong (1982) Cellular mechanisms of neuronal synchronization in epilepsy. Science 216: 745-747.

Uchizono, K. (1965) Characteristics of excitatory and inhibitory synapses in the central nervous system of the cat. Nature 207: 642-643.

Ulinski, P. S. (1983) Dorsal Ventricular Ridge: $A$ Treatise on Forebrain Organization in Reptiles and Birds, Wiley, New York.

Werman, R. (1966) Criteria for identification of a central nervous system transmitter. Comp. Biochem. Physiol. 18: 745-766.

White, E. L. (1978) Identified neurons in mouse Sml cortex which are postsynaptic to thalamocortical axon terminals: A combined Golgi-electronmicroscopic and degeneration study. J. Comp. Neurol. 181: 627-662. 